Josephine Moate \& Hanna Posti-Ahokas

\title{
MODES OF STUDY HANDBOOK FOR STUDENTS AND EDUCATORS
}

Faculty of Education and Psychology Creating Space project 
JYU REPORTS 6

Josephine Moate \& Hanna Posti-Ahokas

\section{MODES OF STUDY HANDBOOK FOR STUDENTS AND EDUCATORS}

\section{FACULTY OF EDUCATION AND PSYCHOLOGY CREATING SPACE PROJECT}

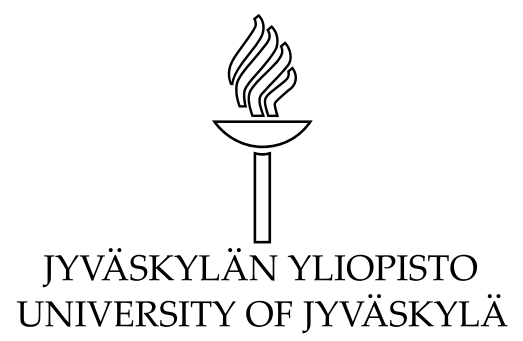

JYVÄSKYLÄ 2021 


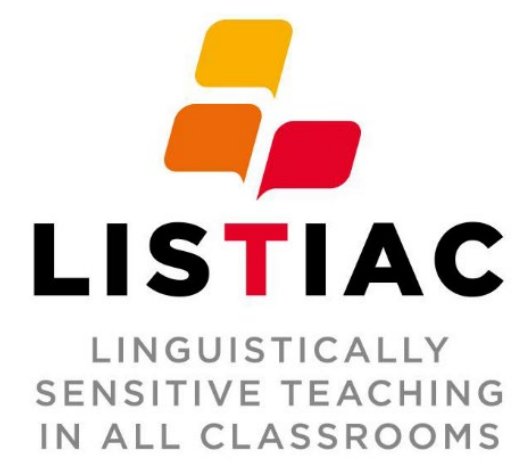

Copyright @ 2021, by University of Jyväskylä

Permanent link to this publication: http://urn.fi/URN:ISBN: 978-951-39-8821-0

ISBN 978-951-39-8821-0 (PDF)

URN:ISBN: 978-951-39-8821-0

ISSN 2737-0046

DOI: 10.17011/jyureports/2021/6

This work is licensed under a Creative Commons Attribution 4.0 International license (CC BY 4.0). 


\section{Contents}

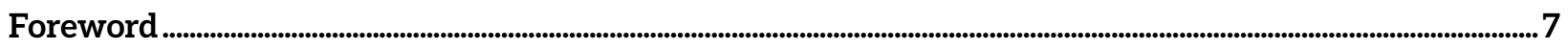

Participating in academic study through multiliteracies and multimodalities......................................................... 9

Creating space for different languages and modalities............................................................................................................. 9

Acknowledgements ............................................................................................................................................................................................................12

Annotated bibliography

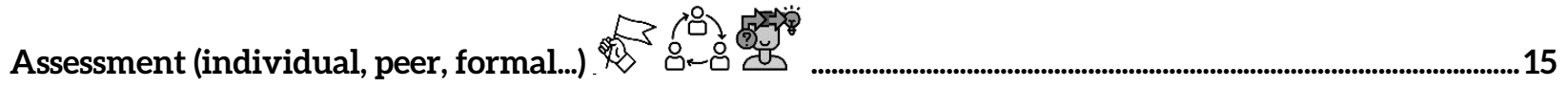

Assignments: learning journals, essays, reading tasks, group presentations

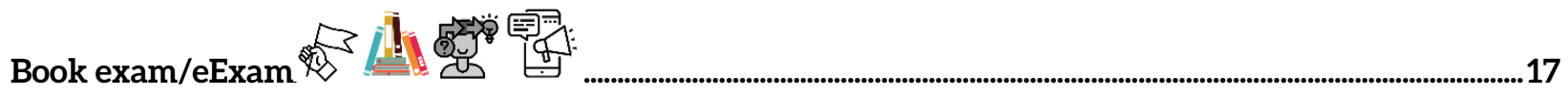

Classes

Conversation mapping or silent dialogue

Creative writing

Critical thinking

Debates

Demos (Demonstrations)

Designing powerful questions

Digital learning environments and platforms

Distance learning 垎 


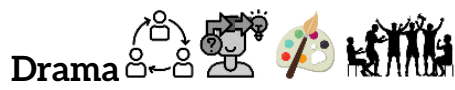

Examinations: individual, written, group oral exam

Feedback (peer, group) 每

Fieldwork 造 \%

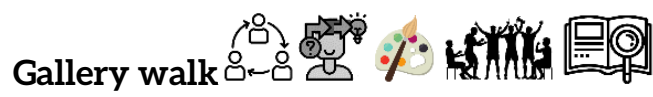

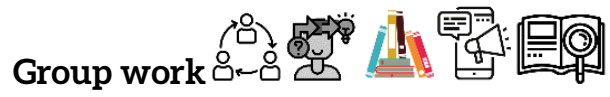

Group presentations 每践

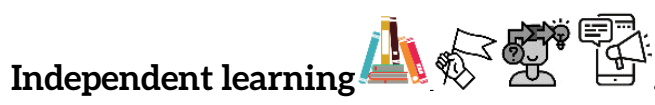

Independent tasks and activities

Infographics

Integrative modes of study

Laboratory work

Learning café and pedagogical cafe.

Learning diary

Lectures

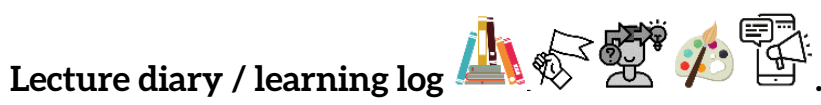


Note-making / note-taking

Online courses

Online discussions

Participation A

Peer support

Photo essay in

Poster presentations 임

Prewriting strategies

Project-based learning

Reading assignments

Reflection 스

Reflective sketchbook 11 .

Research seminars

Selecting and citing academic t1,

Supervision: individual or group 110

Story circles 
Video lecture 110

Video presentation 11 约

Visual methods and tools $\%$

Visual harvesting $\stackrel{1}{\circ}$

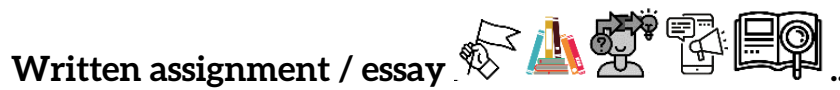

Zines $\%$ 일 


\section{FOREWORD}

\section{PURPOSE OF THE HANDBOOK}

The aim of this handbook is to support the further development of multilingual and multimodal approaches to academic study at JYU. This handbook has been developed within the Faculty of Education and Psychology as part of the Creating Space pedagogical development project during the 2019-2020 academic year, drawing on and developing existing study guides by JYU ${ }^{1}$. We hope, however, that this handbook is useful beyond our Faculty and that it adds language and cultural considerations to the existing study guides. We have provided brief explanations of different types of assignments and academic activities that are part of academic study and relevant to teaching in higher education. We have also included 'good to know' pointers for students and teachers, as well as suggestions for how different languages can be used as resources in academic study, and highlighting ways in which cultural awareness can support academic participation. The call-out bubbles are quotations from students and teachers who have participated in the Creating Space events. We hope that this handbook helps to raise awareness regarding the value and role of different languages, cultures and modalities in academic study and provides useful pedagogical tools for students and teachers.

\footnotetext{
${ }^{1}$ Examples of MODES OF STUDY guidelines on the JYU website https://www.jyu.fi/sport/en/study/study-guide/studying/modes-of-study-1 https://www.jyu.fi/hytk/en/studies/studying/modes-of-study_ https://www.jyu.fi/science/en/study/study-guide/studying/modes-of-study_ https://www.jyu.fi/it/en/study/study-guide-it/studying/modes-of-study_ https://www.jyu.fi/edupsy/en/studies/studyguide/study-instructions/modes-of-study _ https://www.jyu.fi/en/study/new-student-handbook/glossary
} 


\section{LEARNING AS A SOCIAL EXPERIENCE: CREATING KNOWLEDGE AND LEARNING TOGETHER}

We believe that we learn from and with each other. Not only do teachers bring expertise to the learning environment and situation, but so do students. Students today come from all corners of the earth with unique educational and cultural backgrounds. Our objective is to bring the expertise of students into dialogue with that of lecturers and other students, to open our understanding to the diversity of social, political, cultural and economic environments, societies, education and communication. The aim of this approach to education is to prepare our students to be able to work in diverse environments and societies, applying the learning processes and knowledge created in our learning environment ${ }^{2}$.
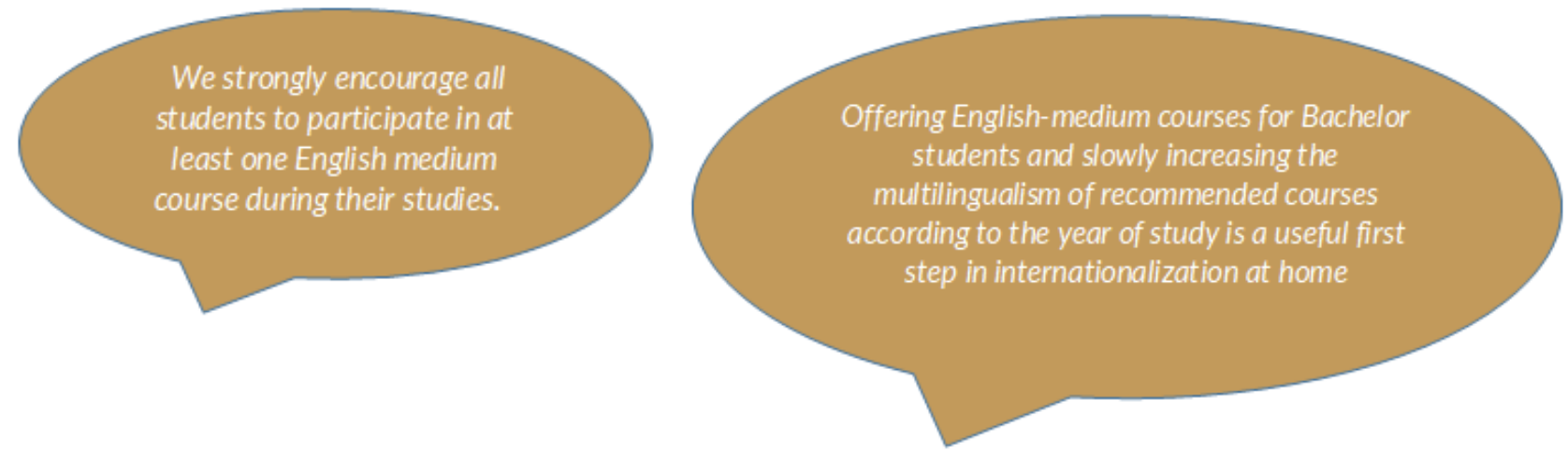

\section{ENTERING ACADEMIC STUDY}

Academic ways of working are often formal and demand a high level of language competence. The value, however, of using and promoting different languages and modalities as part of academic study is increasingly being recognized. Learning how to produce academic assignments requires time and effort. These guidelines should help make it clearer what kind of assignments you might be given during your studies and how to approach these assignments. Academic study, however, is more than learning how to use formal language in specific ways. Academic study also involves the development of thinking skills, reflection and looking from different perspectives, as well as learning how to critique and comment on the work, perspectives and understanding of others. Some assignments outlined in this guide support the development of academic thinking with creative and open-ended assignments. Other assignments deliberately use academic formats to help students develop their own academic style.

\footnotetext{
${ }^{2}$ https://www.jyu.fi/edupsy/en/studies/studyguide/study-instructions/modes-of-study
} 


\section{PARTICIPATING IN ACADEMIC STUDY THROUGH MULTILITERACIES AND MULTIMODALITIES}

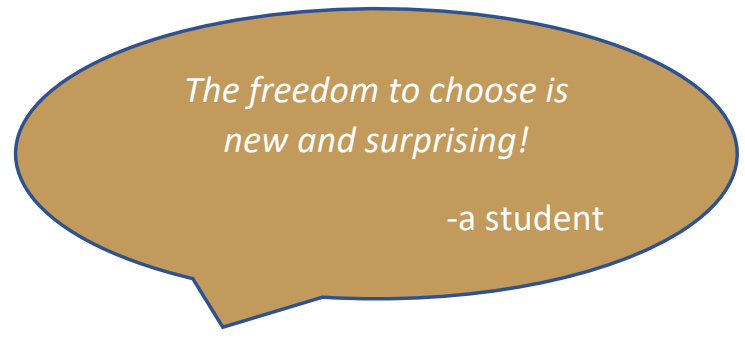

Academic study involves becoming familiar with the ongoing 'conversations' around topics of interest. As with everyday conversations, it is useful to find out what has already been said before adding your own contribution. That said, working out your own contribution to the ongoing conversation is also an important part of academic study. The conversations of academic study differ from everyday conversations in significant ways. For example, academic conversations pay specific attention to what has already been said and by whom, as well as how something is said and how that contribution has been developed and published. This means that, in order to be able to contribute meaningfully to academic conversations, time and effort must be taken to orient to the 'ongoing conversation'.

\section{CREATING SPACE FOR DIFFERENT LANGUAGES AND MODALITIES}

The more languages and cultures that we have as individuals and a community, the more resources we have for developing thinking, for developing understanding and for sharing knowledge. Creating space for more languages and cultures, however, requires reconsidering why and how languages are used within academic communities. It is important and useful to note that different languages provide different perspectives and different ways of conceptualizing. When a community acknowledges the existence of different cultural emphases and priorities, then existing assumptions are easier to identify and critical thinking is enriched. This stance highlights:

- The value of using knowledge published in different languages as well as acknowledging how different contexts are based on different conditions

- The use of different languages within the learning and studying process (e.g. using different languages for thinking, but then planning and structuring assignments in the target language) 
- The value of talking about work in different languages enriches thinking as well as thinking through key concepts in different languages

- Actively identifying and utilizing situations where multilingual/multimodal approaches can be included

To support these, we have included language considerations in the glossary of modes of study. Further resources for learning are also available through the JYU Centre for Multilingual Academic Communication (MoVi) https://movi.jyu.fi/en.

The focus on language(s) encourages a wider discussion on different modes of study. In this handbook, different modes of study include talk- and or text-based modes as well as visual, digital and embodied approaches to learning. Although the academic world is full of strict conventions, students can benefit from using different modes when exploring different ideas and developing understanding. This raises the question of what modes of study do we value? What are the (often hidden) hierarchies between the different modes? What disciplinary differences are there when valuing different modes? Reconsidering the role of language(s) and different modes of study can be helpful for individual and collaborative pedagogical planning.

We hope this handbook supports planning and diversifying assignments between and across courses. Useful questions for teachers to consider are, for example: When is it justified to emphasize and/or evaluate the learning process rather than the learning content/output? How to provide a range of diversified, meaningful learning experiences and studying opportunities across courses? Useful questions for students to consider are, for example: What kind of resources do I have that I can use to support my learning? What learning habits have I developed during my educational journey - which of these are helpful and what new approaches could be developed? As a student, you often know what parts of the studying process you find most difficult, such as starting an assignment, trying to engage with different perspectives, or keeping a record of your understanding and reflections along the way. We hope that the different types of approaches included here will help you to see new and richer ways of approaching academic study.

From an intercultural standpoint, depicting examples of pedagogy and study content opens opportunities for the further development of good practice. Being aware of the different emphases that exist across educational systems, e.g. valuing of arts, digitalization, critical thinking, as well as the languages of schooling, should develop the range of tools we have for studying and working well. The diverse experiences of students and teachers fundamentally influence how academic study is approached and what is considered 'academic'. Sensitivity to our differences and our assumptions should help us as educators 
to create supportive learning environments that enhance communication and participation in academic activities.

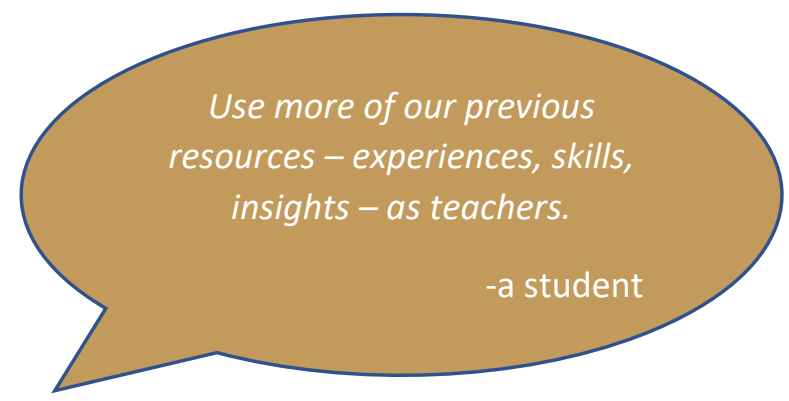

This handbook aims to generate discussion on the potential of diversifying the use of language(s) and modes of study in intercultural learning environments. Interculturality is part of all human interaction. An intercultural approach recognizes the cultural similarities and differences present in our individual identities and learning repertoires. Intercultural competence is about recognition and consideration of our diverse, changing identities. Intercultural pedagogy pays attention to the potential of diversity in ourselves in opening up new perspectives and thus enriching study experiences and learning outcomes. Pedagogical intercultural competence allows us to move away from fixed assumptions and essentialism and thereby gives space for culturally responsive action.

We hope that the readers find the brief descriptions, useful pointers and the 'language and cultural considerations' easy to navigate and feel inspired to continue developing academic study as an individual and community activity. It is our hope that these short sections provide practical guidelines for broadening and enriching what is involved in academic study and how academic study is understood. The symbols alongside the name of each mode of study indicate what is involved in each modality, for example, whether it supports academic reading or collaborative work.

Creating Space Team 


\section{ACKNOWLEDGEMENTS}

The Creating Space pedagogical development project has primarily been funded by the University of Jyväskylä. This handbook is the product of multi-phased collaborative work. Our experience of working with international students was the inspiration for more carefully considering how language and cultural awareness can be strengthened in higher education pedagogy and the value of different modes of academic study. Our grateful thanks to Master's student interns Marianne Jaakkola and Viktoria Edes for your valuable contributions in the initial phases of the project. We thank students for sharing their questions, experiences and suggestions. Doctoral student Bhavani Ramamoorthi joined the team at a later stage and introduced more creative, visual and narrative modes of study, as well as adding picture symbols to support navigating through the handbook. We also offer our thanks to colleagues for sharing their expertise: Panu Forsman, Anna-Leena Kähkönen, Anssi Lindell, Anne Martin, and Selma Närkki. And finally, our thanks to Sirpa Vehviläinen, Emma Pesu, Hanna Korhonen and Vesa Moate for your careful work with the Finnish and English versions of the handbook.

Our warm thanks to the whole team!

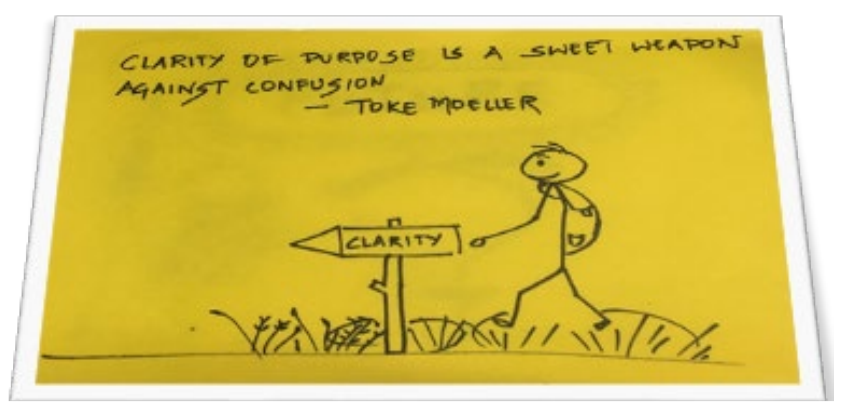

Figure 1. Clarity of purpose. @Bhavani Ramamoorthi 
Table 1. Key symbols.

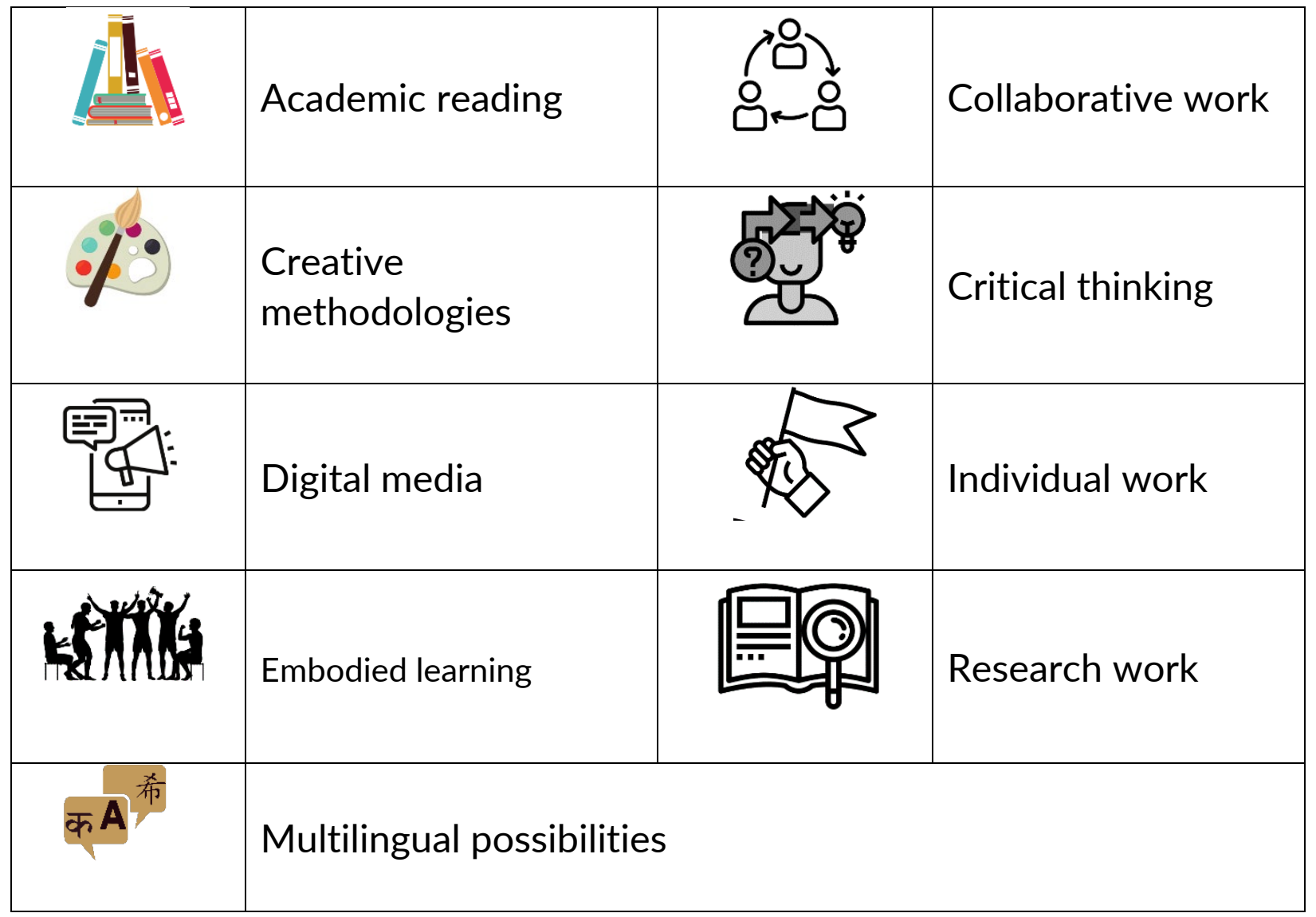




\section{ACADEMIC ACTIVITIES AND MODALITIES}

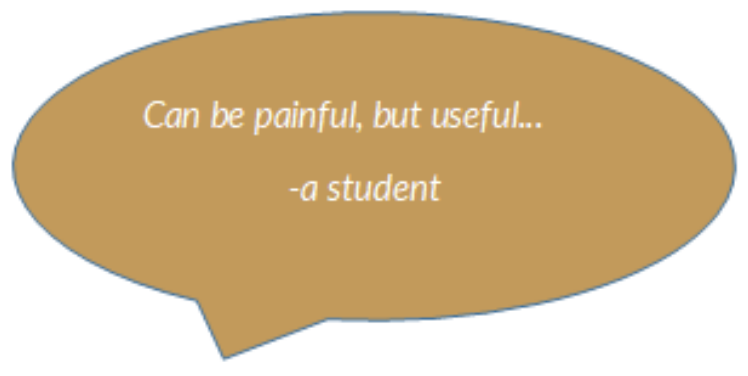

\section{Annotated bibliography 슨}

An annotated bibliography is a list of sources (e.g. books, articles, reviews), as presented in any bibliography, that includes a short commentary (annotation) on each source. An annotation might be a brief summary of the source or it might focus on a theme. An annotation can be descriptive or informative, analytical or critical. If the annotation is critical, it examines the strengths and weaknesses of what is presented. An annotation can also include the student's reflections on the source, e.g. whether it is particularly useful or presents a new perspective.

\section{Pointers for students:}

- It takes time to learn use academic conventions, such as how to present bibliographic references correctly - this is a good assignment for practising that skill.

- This is a great exercise to get started with finding academic sources around a theme and practising academic reading and research skills.

- If you include quotations in your annotation, remember to include the exact page numbers.

- Compiling annotated bibliographies throughout your studies can be a very useful way of gathering your readings and reflections in one place.

\section{Pointers for educators:}

- Make it clear to students whether they can freely decide on the focus of the annotations or whether they are expected to focus on the presence of a theme.

- Students can benefit from seeing a model annotated bibliography.

\section{Language and cultural considerations:}

An annotated bibliography is a good assignment for the inclusion of academic

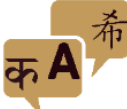
sources in different languages. Students could be instructed to use sources from two or 
three languages with clear criteria as to what kind of source is appropriate, e.g. an academic journal rather than an anonymous text available online.

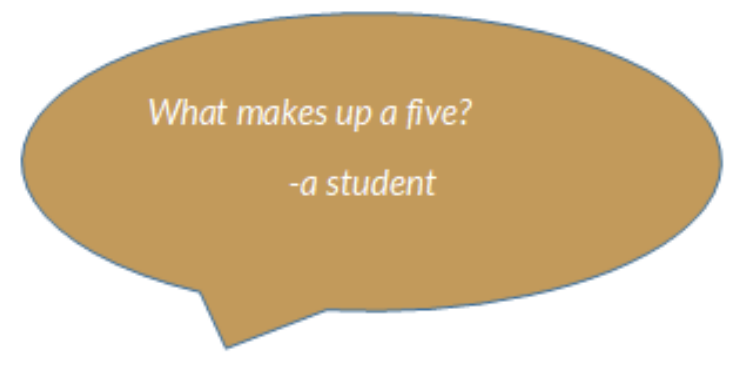

\section{Assessment (individual, peer, formal...)}

Assessment can come in many different forms and at different stages of the learning process, and the criteria for assessment should be appropriate for the study genre, e.g. essay, learning diary, as well as the stage of assessment (during the process, at the end). Final assessment for a course is often based on formative and summative assessment and can include self, peer and teacher evaluation. The assessment criteria are outlined in the curriculum, with detailed instructions provided for each course, and this information should be provided at the beginning of each course. Assessment should help you to recognize what you have already learned and how you have developed, as well as recognize areas for further development.

\section{Pointers for students:}

- Clear criteria are an important basis for assessment. When doing peer (and self) assessment, point to positive aspects as well as areas for development in a constructive manner.

- Take a careful look at the assessment criteria for the different grades and be honest and kind with yourself when grading your own work. Grades above 3 must be clearly justified in your self-assessment as well as peer assessment.

\section{Pointers for educators:}

- All grades must be clearly justified, especially those below 3. Feedback must be given in all cases either in writing or verbally, and the right to receive feedback must be clearly communicated in every course material.

- When using peer assessment, clear guidelines and criteria need to be given to students in order for them to be able to benefit from the task. It is also important to provide the space for individuals to disagree with peer assessment. 


\section{Language and cultural considerations:}

Public assessment might be quite difficult for some participants and some students might be more used to verbal rather than written forms of assessment. Giving constructive feedback or assessment often requires a sensitive and even sophisticated linguistic repertoire. To support positive communication, it can be useful to model different ways of giving feedback and constructive assessment statements.

\section{Assignments: learning journals, essays, reading tasks, group presentations 6}

Assignments form a significant part of course activities and evaluation, and some courses might only use assignments as the basis for evaluation. Whereas some assignments might be given as individual tasks, other assignments will be given as pair or group tasks. All assignments require careful planning and investment of time and energy, but they should also draw on the material and activities carried out during the course. This guide provides descriptions of many kinds of assignments, but you can still ask the course teacher or lecturer to clarify what is involved in the assignment.

\section{Pointers for students:}

- Assignments should support your learning and studying process. Try to understand the aim of the assignment in order to benefit more from the task.

- Understanding how an assignment will be evaluated can help you design your work appropriately.

- Try to manage your timetable well so that you are able to meet the demands of different courses. See the Group work section for tips on working in groups.

\section{Pointers for educators:}

- Assignments that are clear to educators are not always clear to students. It is worth checking with the students that they have understood what is involved in the task and allow for some initial planning time in-class.

- If many out-of-class group assignments are given, students can struggle to meet all the demands that are made of them.

\section{Language and cultural considerations:}

Assignments are rarely completed (well) in one go. Consider the different stages 
with the process. For example, visualizations, concept mapping, and even thinking through different languages can help move forward with an assignment.

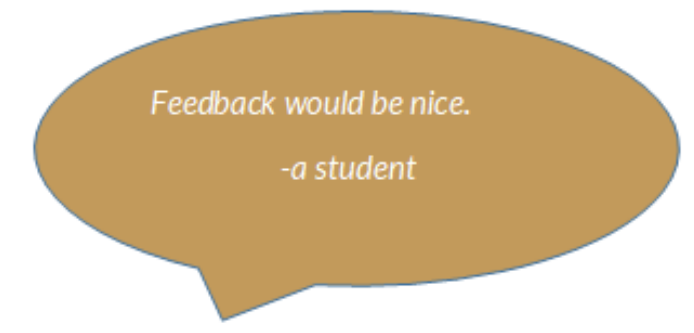

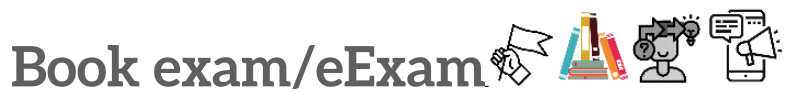

Book exams or eExams are used in some courses and might be one part of completing the overall course. Some courses can be taken independently with an exam or eExam. More information on e-exams at JYU is available via this link: https://help.jyu.fi/jp?id=kb_article\&sys_id=b07e69d2dbf6d4d07b7b2b4305961967

\section{Pointers for students:}

- If you are given a book to read, try to identify the key ideas and underlying assumptions of the text.

- Textbooks tend to introduce snapshots and different perspectives of a topic or field, with little space for critical reflection or insight into how ideas have developed over time.

- Academic books try to provide a holistic view of phenomena, including ideological roots, practical implications and critical assessment. In both cases, the task of the reader is to critically understand and respond to the ideas presented in the book.

\section{Pointers for educators:}

- Students may find it hard to know what is important in the content and in how much detail they should study.

- It is worth being aware of the different types of books that can be used to inform academic study. University textbooks are less likely to encourage critical reflection, whereas academic books should make their underlying principles and assumptions available to the reader, but readers have to know where and how to find them in the text!

\section{Language and cultural considerations:}

Book exams are not universal features of higher education. Some students may

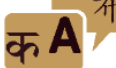
be unfamiliar with the requirement to read and respond on the basis of one source, expecting instead to have to draw on a wide range of reading. Some students might be unfamiliar with having to read a whole book as they are used to studying handouts provided in anticipation of exams. 


\section{Classes}

Most courses involve lectures and/or workshops, seminars and/or reading circles often referred to as 'classes'. Classes usually comprise smaller groups of approximately 20 students. Classes may be preceded by required readings, so that students can prepare for class discussions based on lecture or reading material as well as students' own questions. Discussion usually plays a key role in classes, so students are expected to be present.

\section{Pointers for students:}

- The number of classes and contact hours of a course only represent a small proportion of the total workhours of the course.

- When preparing for a class, consider beforehand what questions you would like to ask and what you would like to gain from studying the topic.

\section{Pointers for educators:}

- Class discussions can benefit from students knowing beforehand the focus of the discussion. Small group discussions can prepare the way for whole class discussions.

- Being aware of different discussion roles can help to ensure that students participate in different and varied ways in class discussions.

\section{Language and cultural considerations:}

It can be worthwhile using a little class time to identify the key concepts of the

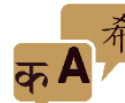
course and how they are defined. Students can also explore whether equivalents exist in other languages and whether different languages conceptualize the phenomenon in the same way. For some students, big group discussions can be intimidating, especially if the themes and language are unfamiliar. Students that are used to participating in big group discussions might dominate class discussions. Agreeing on basic ground rules can help to develop the quality of the discussion, e.g. agreeing that everyone will contribute at some point during the discussion and emphasising that different perspectives are welcome. Students can also benefit from having time to prepare their contribution in or before the class. 


\section{Conversation mapping or silent dialogue 8 임 $\%$}

Conversation mapping can create an energetic, dynamic, thought provoking discussion without talk. This approach is a core practice of systematic thinking and seeks to generate a diverse set of ideas on complex topics. Participants gather around a large piece of paper that serves as a visual tool for further reflection and discussion. As participants add their contributions to the paper, patterns and/or connecting threads often become visible. The different perspectives provide ideas for collectively responding to a complex issue. The following link provides a useful overview of how to implement these approaches in practice: https://philipwallis.wordpress.com/2012/02/14/ conversation-mapping/Silent group mind mapping is a slight variation of the same activity with the same purpose in mind. Both activities allow physical movement and collaborative thinking in parallel.

\section{Pointers for students:}

- Each student can choose their own colour for adding comments to the conversation map. Pause and reflect before adding to an existing thread or starting a new thread of comments.

- Avoid drawing connections between different threads during the initial writing phase as this might confuse the underlying assumptions. Possible connections between threads can be addressed during the discussion that follows.

\section{Pointers for educators:}

- Emphatic questions or statements at the centre of the conversation map help generate varied thought processes. Usually, the questions on each map are under one umbrella theme.

- Walk around and see if students are comfortable doing this activity in silence. Sometimes students start conversations, but the aim is to communicate and build ideas through written language, adding new thoughts and ideas while staying present in the activity. Encourage students to walk around and contribute to each conversation map.

\section{Language and cultural considerations:}

This activity can be adapted to any common working language among groups.

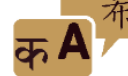

Students may be unfamiliar with this activity, but with clear instructions they usually adapt to it and participate well. This mode of study works extremely well with multicultural groups as it changes the pace of the dialogue and allows time for participants to reflect before adding their contribution. In multilingual groups, the conversation maps can have contributions in different languages, and during the follow-up discussion students can collect the diverse ideas, questions and opinions presented in different languages. 


\section{Creative writing}

In creative writing (or literary arts), pieces of art are composed through language and the written word. In academic studies, creative writing assignments may vary from writing journals or personal stories to quick scribbles, lists or blogs. These texts can deal, for example, with different learning experiences, personal life, identity and values. According to research, autobiographical creative writing is especially effective for supporting personal and professional growth, with positive effects on well-being. Creative writing can be used at the beginning of a course to help students tune in and set their goals and expectations (e.g. lists, free writing), during a course as a reflective assignment (e.g. letters, short poems), or at the end of a course (e.g. short story based on personal experiences relevant to the course content). Creative writing can bring a sense of playfulness, enjoyment and flow into student life.

\section{Pointers for students:}

- Try not to overthink the piece of art you are about to create; focus on the process: creative writing allows you to play with words and to forget about the strict rules of traditional academic writing.

- Don't worry about mistakes or writers' block; just allow yourself to start and leave the fine-tuning till later. The first draft is rarely perfect: you can always go back over and improve your text later.

\section{Pointers for educators:}

- Using creative writing methods in your teaching can inspire your students and spark their creativity. A wide range of options can be explored, from poems and short stories to imaginative dialogues and free writing (mind flow).

- When using creative writing to learn, the emphasis is on the process, not on the end result or perfect language.

- Offer a concrete starting point to get the writing process going and leave space for the students' own inspiration. Learning through creative writing is more efficient when a social element is added, such as peer discussion, sharing stories, etc. 


\section{Language and cultural considerations:}

Creative writing can provide valuable opportunities for students to try out different voices and to explore ideas through their own literary creations. Creative writing is a place to be playful and to have fun with language, and different languages can be incorporated into the text. Participants might need to be reminded that this process can help their development and learning. Writing about their backgrounds, sharing and discussing their personal stories with their peers, and discovering the joy of playing with words can bring new insights to each student and help them to cross intercultural boundaries.

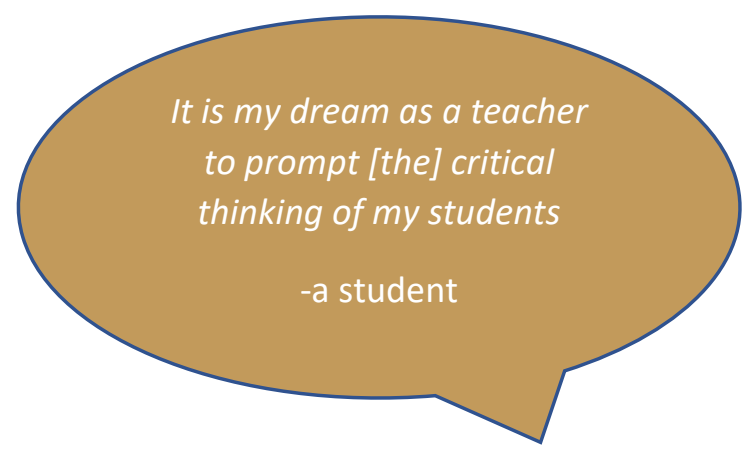

\section{Critical thinking}

Critical thinking is the basis for academic work and study. Critical thinking involves looking from different perspectives, making assumptions explicit and asking difficult questions. It is an applied learning process that develops through practice. Thinking critically requires a combination of skills, such as inferring, analysing and evaluating, as well as open mindedness, self-efficacy and inquisitiveness. 'Why' and 'how come' questions can be a useful starting point for critical thinking.

\section{Pointers for students:}

- Critical thinking is present in different ways in academic study. Developing critical thinking skills takes time and practice. The different types of assignments that belong to academic study should help you to develop critical thinking.

- It can be useful to see how different researchers write about the same topic and try to identify the similarities and differences in their approaches and perspectives. You might notice that one researcher emphasizes one point that is absent altogether from another researcher's text.

\section{Pointers for educators:}

- Keep in mind that learning involves changing your mind and making mistakes. 
- Sharing and criticizing views within the public space of a classroom can be difficult for some students, especially if exploring different perspectives is not a welcome part of the classroom culture.

- Students often benefit from hearing the critical reflections of others, which can help develop their own critical perspective.

\section{Language and cultural considerations:}

Critical thinking can be easily confused with criticism, i.e., claiming that someone or something is wrong, rather than digging behind first impressions to really understand what is being said and to provide a well-thought out response. Critical thinking can be especially challenging for people that are used to reproducing the words and ideas of respected authorities. Thinking through different languages can be one way of critically thinking about different perspectives. Critical thinking can also give rise to new questions and invites students to more deeply consider whether and how they agree or disagree with the ideas of others. The Manchester Phrasebank provides a range of English phrases that can help express critical thinking: http://www.phrasebank.manchester.ac.uk/beingcritical/

\section{Debates}

Debates are public, formal discussions that bring together contrasting views on a particular topic. Participants are expected to put forward an argument within a given time justifying their point of view or stance. Debates are used to prepare the floor for a wider discussion in which more voices can contribute. The chairperson of the debate is usually responsible for introducing the speakers as well as for mediating the following discussion. Debates involve teamwork, quick thinking, and detailed 'post-mortem' analyses (post-discussion of the content and flow of the debate).

\section{Pointers for students:}

- Debates should help participants to think from different perspectives and to acknowledge different views.

- The content should be logical, i.e. arguments developed in a clear, reasonable and plausible way, supported by real-life examples and explanations. It is also important to support your fellow debaters and maintain consistency by keeping speeches and key points on topic.

- As a speaker, you must properly use your allotted speech time and focus on the relevant content, arguments and rebuttals. The speech should have a clear structure and purpose, making it easier to follow and more impactful. 


\section{Pointers for educators:}

- Students may have significantly different experiences of debates and debating, and this can influence their readiness to participate. It might be useful to initially invite participation on a voluntary basis and to be aware of the skills required for effective debates.

- In argumentation, presentation and language both play important roles. As not all participants may have the same level of elocution or confidence, supporting good preparation is important.

- Clearly defining the structure and guidelines of the debate is essential in order to have an impactful, participative discussion.

\section{Language and cultural considerations:}

Debates are an important part of democratic societies and can play a significant

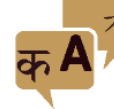
role in intercultural dialogue. If participants have significantly different language repertoires this can cause significant difficulties in the debate, for example, creating power imbalances. Preparing for debates through role play, practising formal speeches, and preparing for potential questions can help overcome the challenges of debates. The chairperson could also help facilitate the discussion by asking for questions to be written on a digital canvas, such as Padlet, and holding short breaks to give speakers a chance to prepare their responses. As one goal of debates is to generate solutions to shared challenges as well as to develop public speaking skills, it is important to reflect on what was learned through this experience and to identify areas for further development.

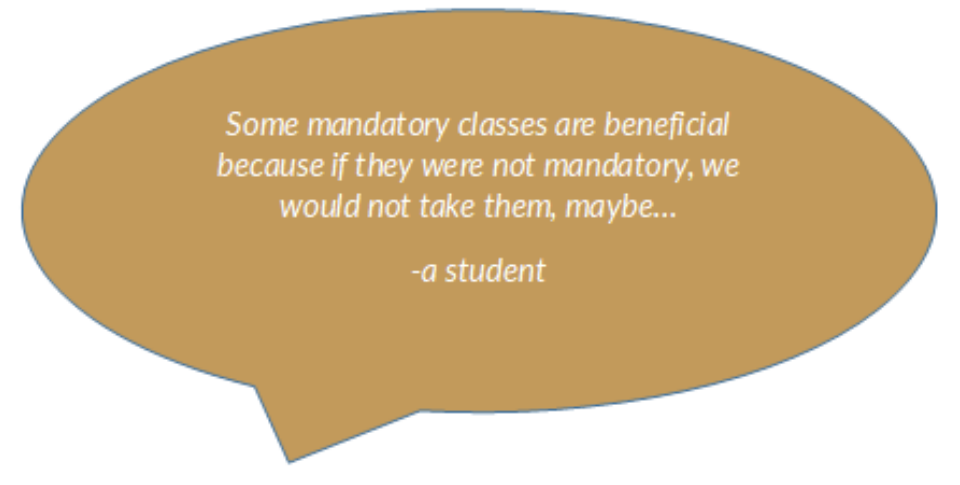

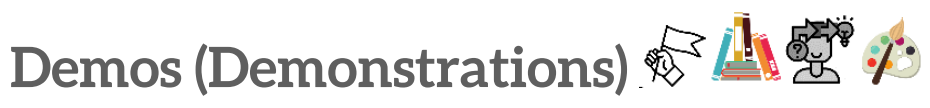

The purpose of demonstrations (demos) is to explore and examine the content of a lecture in more detail in relation to the area of education the students are specializing in as well as the literature they are reading. Sometimes, tasks or key questions assigned in 
lectures are discussed in demos and, during pedagogical training, exercises given during lectures can be practiced in demos to help gain better understanding. Although a number of different lecturers might give lectures during a course, demos are usually carried out with the same teacher and group of students.

\section{Pointers for students:}

- Good notes from lectures and regular reading can support participation in demos, which in turn provides a shared space for developing understanding, asking questions and clarifying key points and course requirements.

\section{Pointers for educators:}

- Students can benefit by being prepared in demos for forthcoming lectures, not just reflecting on lectures that have been given already.

\section{Language and cultural considerations:}

Demos are similar to tutorials or other small group sessions that work with the material presented in lectures. Demos can be useful contexts for creating space to work with and through different language repertoires and to explore ideas using different modalities.

\section{Designing powerful questions}

Designing powerful questions as a collaborative exercise can build greater connections and sense of purpose as a community of learners explores a topic together. Powerful questions generate curiosity and reflective conversation, making underlying assumptions visible, and creating new possibilities for exploration and learning. A thread of powerful questions is formed as the structure, scope and underlying assumptions of questions are modified, helping to focus and deepen the responses of participants and enriching the collective thinking process.

\section{Pointers for students:}

- This is a pedagogy for deepening the inquiry process in learning.

- Play and experiment with different question starters (how, why, what if...) to see how they broaden and alter the scope of your discussions.

- Discovering the assumptions behind questions should help you broaden your awareness of the space between self and others and how we perceive and understand this relational space. 
- Becoming more aware of the power of questions can help you to ask further questions and to be an active, rather than passive, participant in the learning process.

\section{Pointers for educators:}

- Designing powerful questions is a step towards building empowering learning environments. Students might, however, need help to see the purpose and power of this activity.

- This collaborative exercise could be introduced at the beginning of the course to bring in student involvement in designing the scope and content of group work or after introducing a concept, to deepen the inquiry process.

- When students feel connected to the questions they have designed collectively, they feel ownership of the learning process and the course content.

\section{Language and cultural considerations:}

Powerful questions can be designed and pursued in any language. In a multilingual community, participants can compare and contrast whether assumptions are the

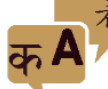
same in different languages, for example, whether education is a natural or cultural process, or whether development and learning are the same process. Participants can design questions in different languages to see whether and how the questions work in different languages and cultural contexts. Often in academia more time is spent discussing pre-designed questions or seeking solutions to a question posed by the educator. Designing powerful questions could be a new experience in class interactions.

\section{Digital learning environments and platforms}

Digital learning environments are often useful for distance studying and non-classroom based activities. Some courses are fully conducted via digital learning environments (often Moodle), whereas hybrid or blended courses combine face-to-face and online interaction. Online learning environments can provide a repository for key course materials as well as an interactive space for student discussions. Increasingly, assignments and evaluations are also implemented through digital learning environments. General Moodle guidelines can be accessed through https://www.jyu.fi/digipalvelut/en/guides/moodle-guide

\section{Pointers for students:}

- The more you enter into the digital learning environment, the more you can gain. Don't be afraid to share your thoughts, even if they are not fully developed. 
- Take advantage of the different templates, formats and structures that are available in the online space, e.g. chats, discussions.

- Practice different ways of contributing to online processes and think about the different roles that are part of online learning.

\section{Pointers for educators:}

- Digital learning platforms can give greater freedom to students to choose when they contribute to course discussions.

- Students can benefit from the development of a sense of community in online learning contexts, as well as offline. It can take time for students to learn how to navigate their way around different digital learning platforms.

\section{Language and cultural considerations:}

Digital platforms are a great tool for collaborative learning. For many students the physical presence of a student group is removed and they are sometimes more participative in online spaces when they can take time to think and prepare their response. Digital platforms can also provide spaces for multilingual discussions, online translation tools and dictionary resources. As with in-class communities, it can be helpful to share ground rules for interacting in the digital space, for example, how many contributions are expected in group discussions and what to do if problems are encountered.

\section{Distance learning 总}

Distance courses do not require participants to be in the same physical space at the same time, although there might be regular online meetings. Distance learning courses often allow participants to do courses completely or partly independently. Nowadays, distance learning courses often use digitally-mediated learning platforms, resources and activities to support course activities. See also Online courses

\section{Pointers for students:}

- Even if you are participating on a distance-learning course, it can still be worthwhile talking about the materials you are studying with a friend or other participant on the course.

- You might also benefit from using different modes of learning, e.g. graphic organizers, infograms or keeping a learning journal to study the contents of the course and to really enter into the learning process. 


\section{Pointers for educators:}

- Some students can feel isolated and struggle to maintain their commitment to a course without a sense of community.

- Community-building activities can include informal as well as formal discussions via digital platforms, as well as pairing course participants so that they have a study companion in the course.

\section{Language and cultural considerations:}

Digitally mediated and distance courses offer little insight into the study क A experiences of the students unless their experiences are explicitly sought and shared, and misunderstandings can occur more easily than in face-to-face contexts. Digital platforms can benefit from the use of ground rules, and using different modalities within tasks can also help participants enter into their studies.

\section{Dramasian}

Dramatizing concepts and scenarios can bring theories to life and help students to develop their ability to put theory into practice. Drama can also be an effective tool for introducing, elevating and assessing a wide variety of inter- and intra-personal skills. The flexibility of drama can provide a low-cost method to use time and space in a deliberate, pedagogically advantageous way and can encourage creative responses to difficult issues.

\section{Pointers for students:}

- Some students enter into drama activities more easily than others. Even if you are not keen on acting, observing how others participate can help provoke and develop your own thinking.

- It is important that all participants are respected during the study activities, whatever role they choose to take.

\section{Pointers for educators:}

- Drama offers many different opportunities for participation through creative production, critical direction and reflection.

- Allowing participants the freedom to decide how they will participate in a dramabased activity can be important, as well as ensuring that the different roles and forms of participation are respected. 


\section{Language and cultural considerations:}

Drama provides a space for the active use of different languages in the creative exploration of theorizations as well as practice. Students that are not used to drama-based methods can benefit from low threshold activities to orient them to the use of drama. Briefly outlining the purpose of dramatic activities can also help participants recognize the academic value of this creative approach to support critical thinking.

\section{Examinations: individual, written, group oral exam} 急:

Examinations, typically held at the end of a course of study, are a formal approach to the evaluation of learning. As with other modes of study, examinations can also be implemented through different modalities, such as written or oral examinations or individual or group examinations. Sometimes, exam questions might be made available before the exam itself, other times only the area of examination is known prior to the exam. More information on exam procedures at JYU is available from this link.

\section{Pointers for students:}

- Take time to prepare for the exam without exhausting yourself beforehand. If possible, look at earlier exam questions and plan how you would answer them using the material from the course.

- Always remember to carefully read the exam questions as well as the instructions for answering them.

\section{Pointers for educators:}

- Students should be aware of the evaluation criteria for each exam, as with all assignments.

\section{Language and cultural considerations:}

The formal nature of examinations can intimidate some students but, with practice, this skill can be developed. If the examination format is unfamiliar to students, share sample questions and model how to approach constructing a response. 


\section{Feedback (peer, group) 总品的}

Feedback is an important part of the learning process and should be beneficial for those that give as well as receive feedback. Although feedback is often associated with assessment, feedback is usually given during the studying process so that it feeds into ongoing activities. It is often useful to give feedback from different perspectives and students can suggest what kind of feedback would be most helpful. Connecting the feedback with the stage of the studying process is important. When beginning to generate ideas for an essay, feedback can help the student to develop their ideas further or choose between different ideas. If an essay is almost finished, feedback from a critical friend can help identify any parts that need clarification or correction.

\section{Pointers for students:}

- When commenting on someone else's work, look at the strengths and weaknesses of their work and offer some suggestions for modification.

- Try to be kind but clear. Following the 'sandwich method' is often a good idea: start with some good points - then comment on any weaknesses, offering suggestions for improvement - and finish with a positive comment.

- Ideally, feedback will help you to see your work from the outside and make it easier to develop your work further.

\section{Pointers for educators:}

- Giving and receiving feedback should be a meaningful part of the studying process, helping students move towards the goals of the course and better understand their own development.

- Using feedback criteria can help students practice and focus as they give and receive feedback.

- It may be beneficial to inform students that it is up to them to decide how they respond to feedback.

- Turnitin can be used as a technical tool for giving feedback.

\section{Language and cultural considerations:}

Receiving critical feedback from peers is not always an easy process, although learning to listen respectfully and respond constructively to feedback is an essential skill in higher education and future workplaces. Using critical feedback criteria, or developing the criteria with the students, can facilitate the giving and receiving process. Modelling how feedback can be given and received can be useful when working with intercultural student groups. 


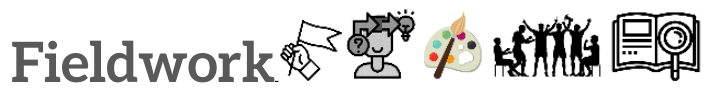

Fieldwork involves physically going 'into the field', i.e. an environment away from the confines of the university where the area of interest is part of the natural environment. If the purpose is to examine the natural environment, a field trip might be to a forest, peatland or stream. In education, a field trip can also be to an educational setting, such as a school, daycare or museum in order to collect social data. A wide range of different methods exist for collecting data as part of fieldwork.

\section{Pointers for students:}

- To get the most from your fieldwork, prepare how to collect the data beforehand. Know the purpose of the visit and what is expected from you. Be aware that when you enter a field environment you change it in some way. Ideally, the disturbance is minimal.

\section{Pointers for educators:}

- Students often benefit from basic guidelines on how to conduct a field trip as well as clarification of the purpose of the work and their particular roles.

\section{Language and cultural considerations:}

Participants will have a wide range of cultural experiences and it should not be

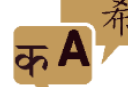
assumed that everyone knows how to carry out fieldwork without some guidance on what to expect and how to work correctly and effectively, e.g. how to interact with the community, how to take notes, what might be inappropriate, such as taking photographs of children without permission, whether different languages can be used to ask children about their experiences, and how to report what is shared.

\section{Gallery walk}

In a gallery walk, space and movement are used to structure the content and flow of discussion by changing the focus of students' attention as they move to different focal points or displays. Displays might include, for example, pictures, questions, posters developed in small groups by the participants, or people (e.g. living library, visiting experts). 


\section{Pointers for students:}

- Make sure you are aware of the purpose of the activity and the guidelines for how the activity is organized.

- Covering a lot of information in a short space of time can be overwhelming; therefore, it can be useful to take notes during the gallery walk as a record to return to.

\section{Pointers for educators:}

- Pacing is an important consideration in a gallery walk - knowing how long to stay focused on one point and when to move on. Clarify whether movement is controlled, e.g. moving on after 10 minutes, or freely decided by the participants.

- This could work as an effective strategy for sharing research work and for team members sharing comments, ideas or questions after the gallery walk.

\section{Language and cultural considerations:}

A gallery walk is a good environment for introducing and benefitting from

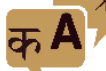
different languages and modalities as well as creating a more informal atmosphere for participants to exchange ideas and to become familiar with each other's work.

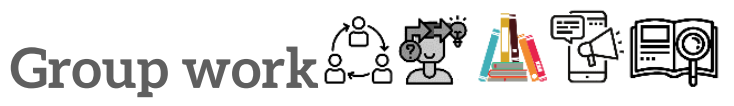

Group work should promote interaction between students and between the students and the teacher with respect to the course content. Ideally, group work supports the development of innovative ideas and learning from each other. In many courses, group work can lead to a co-authored presentation or written assignment with groups working with different topics based on their readings and discussions. Group tasks can include planning, retrieving and distributing information, drafting texts, editing and presenting the work. Each student is expected to contribute to the work and the entire group is assessed jointly on their output. Peer evaluation at the end of the group task might focus on how the group functioned and what was achieved.

\section{Pointers for students:}

- Begin by dividing the work based on the preferences and strengths of your group members.

- Be clear about what has to be accomplished by whom and by what date and create a comprehensive agenda that is shared by all. 
- Schedule regular group meetings to discuss what has been done, give constructive feedback to each other, and evaluate the progress before dividing the workload for the next step.

- Not all group members have to be physically present at all meetings, take advantage of Skype, Zoom, Google Drive and Microsoft Teams.

\section{Pointers for educators:}

- Clear instructions help students know what to do and what is expected of them.

- Providing or agreeing ground rules on how to share the work and allocate tasks, e.g. who has responsibility for what, on agreeing on the deadlines for each work stage and the modes and place of delivery, and on sharing info within the group can help the participants focus on the task.

- Organizing group meetings can be challenging due to group members' different schedules.

\section{Language and cultural considerations:}

Group work should be an opportunity to practice interpersonal skills in a safe environment. Participants can benefit from rotating roles and responsibilities within the group. Be aware that group work is not common to all educational cultures. Agreeing on ground rules and schedules can help avoid unbalanced workloads within the group. Group work provides excellent opportunities to draw on the diverse linguistic repertoires of group members when gathering and presenting ideas and information.

\section{Group presentations}

Group presentations are co-authored products that benefit from the strengths of individual group members as well as thinking together. The content of a group presentation depends on the instructions for the task, but a group presentation is an opportunity to explore from different perspectives and to concisely present the understanding that has developed through the task.

\section{Pointers for students:}

- Make sure that all group members understand the aim of the task and take time together to decide how this can be achieved using the different resources of the group.

- Be aware of the different preferences and strengths of group members and arrange a schedule that is based on clear goals. 
- Constructively give feedback to one another and intelligently use digital tools to facilitate communication and collaboration, e.g. keep a log of what activities need to be done, by whom and when.

- It is important that group members continue to communicate throughout the task - if something is unclear, ask and practice the presentation together.

\section{Pointers for educators:}

- Providing clear instructions regarding the purpose, timeframe and assessment criteria for a group presentation should help students to work together to meet the task requirements.

- Students can also benefit from agreeing on ground rules outlining how they are to work together, e.g. how to ensure that all members contribute to the task and how to resolve disagreements.

- Ensure participants have sufficient time to put together their group presentation; otherwise the quality of the task will be compromised.

\section{Language and cultural considerations:}

Group presentations provide useful opportunities to draw on the diverse

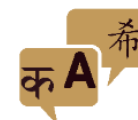
linguistic repertoires and strengths of group members. All members should benefit from sharing ideas and understanding if it is recognized that the task is an opportunity for learning, not just a demonstration of existing expertise. Ground rules can help groups to cohere, especially if an intercultural group is working together for the first time.

\section{Independent learning 1}

Some courses are organized as independent courses, meaning a student can complete them independently by either taking an exam or writing an assignment. The modes of study are defined each year in the Study Programme. Please see the instructions of each course if you need to discuss the assignment with the teacher before starting it.

\section{Pointers for students:}

- You may be required to dedicate a certain number of hours per week to independent course work and to meet with the teacher or communicate with them by email with any questions or clarifications as needed.

- In many cases, independent courses can be enrolled on at any time and you can study at a pace that suits your schedule. Look at your existing schedules and plan an independent study module that suits your study goals for the semester. 
- It can be helpful to collaborate with another student on the independent course to set shared assignment deadlines and keep motivated.

\section{Pointers for educators:}

- For independent courses, it is essential that the learning goals and content are clear and nothing is left ambiguous for the student.

- In addition to the individual work, participants can benefit from meeting with the teacher in group meetings or at least in an initial course orientation session.

\section{Language and cultural considerations:}

Many students are used to structured courses with teacher interaction rather

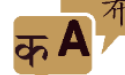
than an independent study course. If independent study is new to a student, it is important to recognize that a regular study schedule and self-motivation will be needed to complete the course successfully. Providing study checkpoints can also help to orient students to the flexibility and demands of independent study over an extended period.

\section{Independent tasks and activities}

An essential part of studying is developing the ability to work autonomously and complete tasks and activities independently. Independent tasks and activities provide opportunities for students to critically engage with the course contents.

\section{Pointers for students:}

- Take time to complete independent tasks and activities. This is an opportunity for you to think through what you know and how you are studying and developing through a course of study. Try out different study methods to help develop your thinking and to broaden your range of tools that support your study.

\section{Pointers for educators:}

- Students can benefit from understanding how independent tasks and activities feed into course activities. It is also important to tell students whether independent tasks and activities are formally assessed or whether they are an obligatory part of the course without being part of the final grade. 


\section{Language and cultural considerations:}

Consider how different languages could be used and which language(s) and modes of study best support learning. It can be useful to think through a different language to develop a different perspective. When mapping understanding, use a language(s) that is comfortable to work with. When starting to prepare a formal assignment that is to be submitted, check what key concepts and terms are in the target language. When the content is clear, try to start thinking through the language that the final assignment will be presented in.

\section{Infographics}

Infographics use a wide range of formats to visually present and represent information. Infographics can be an effective way of engaging with information as well as demonstrating and sharing understanding. Producing an infographic requires time and careful consideration of what to present, how to indicate relationships between different items of information as well as how to represent the bigger picture. Ready-made templates for infographics are available from: Canva, Easelly, Infogram, Piktochart and Venngage.

\section{Pointers for students:}

- Infographics provide opportunities to think critically in different ways.

- Look at different types of infographics and consider which ones make the most sense to you and what kind of infographic you need for the topic, theme or issue you are working with. Try out different ideas before finalizing your decision.

\section{Pointers for educators:}

- As an approach to learning, infographics draw on visual literacy skills. Developing an effective infographic requires understanding of the information as well as the significance and relevance of the information.

- Providing a model infographic can help students orient to their use and role in study.

\section{Language and cultural considerations:}

Less language is needed to produce an infographic, although it nevertheless

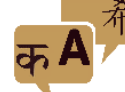
demands careful thought, preparation, understanding and presentation skills. Students used to oral or written tasks should benefit from a brief discussion on the value of infographics as a presentational format. Infographics can also create creative opportunities for the incorporation of different languages. 


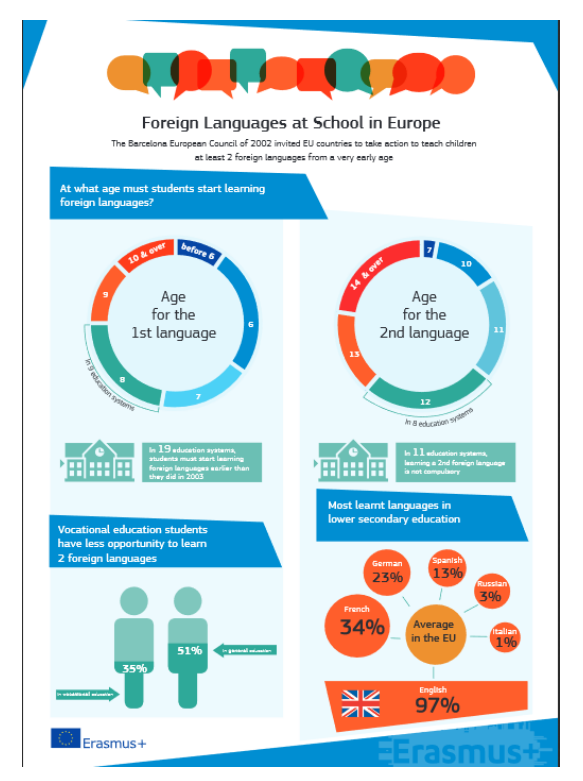

Figure 2: An example infographic on national language policies published online https://eacea.ec.europa.eu/nationalpolicies/eurydice/sites/eurydice/files/infographic_languages _2017_09_25_0.pdf

\section{Integrative modes of study}

Integrative modes of study involve developing a piece of work across courses. For example, the readings from one course can support discussion and written tasks in another course, or a lesson plan developed in one course can be used and developed further in teaching practice. Integrative modes of study ideally support a more holistic approach to studying as well as encouraging students to examine a phenomenon from different perspectives.

\section{Pointers for students:}

- Ideally, different courses should complement each other during your studies, but it is often up to you to make the connections and to benefit from them. Integrative modes of study ideally give you the space to think more deeply. Take the time to critically consider how the content area of one course connects with earlier courses that you have studied. As making connections becomes a habit, it is easier to see how the different parts of your studies fit together. 


\section{Pointers for educators:}

- Some students find it much harder than others to see connections between different courses of study. What can be obvious for an educator can be a mystery for students.

- If possible, allow students to make the connections with other courses or areas of study at the outset or conclusion of your course to help them to continue building the bigger picture.

\section{Language and cultural considerations:}

The shared focus of integrative modes of study should support academic language development, as key concepts are re-visited and expanded. Integrative modes of study should also help develop academic thinking as students return to key concepts and work out how to explain connections, contradictions and critical considerations. Highlighting key words and phrases or developing a word bank can help students become more conscious of the language they are using. Word banks can be mono- or multilingual, hand-written or digital, or creatively or conventionally presented.

\section{Laboratory work 选 学品}

In a laboratory investigation, students can work on exercises independently or in groups. The aims of laboratory work are to put experimental methods of the natural sciences into practice, to get to know laboratory equipment, and to learn how to analyse and report experimental results. In teacher education, laboratory studies are part of learning pedagogic styles relevant to the natural sciences.

\section{Pointers for students:}

- In the laboratory you have a double role: you are performing an investigation using your scientific skills as well as thinking about the skills and learning opportunities applicable to the school context.

- While making notes on the phenomenon you are experimentally investigating, also make notes on the scientific skills you think this experiment would help children work on. For example, is it about following instructions precisely? Or finding your own solution? Or comparing different experimental conditions and making assumptions about the cause of a reaction?

\section{Pointers for educators:}

- Some students come with an expectation that any quantitative study is beyond their ability. Young learners are unlikely to grasp the numerics of an experimentally 
deduced connection, but observing a simple relational connection can be a positive learning experience for the pupil. If working with students on laboratory tasks that are not suitable for younger learners (e.g. using potent chemicals, independent use of matches, or difficult concepts), make this clear to the students.

- Work together on what reporting results can look like and be explicit about connecting the experimental data (students' observations) with a theoretical model (a prediction that was made and whether the data fits the prediction).

\section{Language and cultural considerations:}

Laboratory investigations usually take shape around a research question. If the

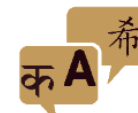
question is implicit ('Let's find out about the properties of different types of paper'), it is helpful to start by breaking the topic down into practical questions ('How much water can each type of paper absorb per $10 \times 10 \mathrm{~cm}$ sample?') that focus the investigation. Laboratory directions are of two general types: recipe (think cookbook), in which a stepto-step procedure is strictly followed, and open-ended, where students are given considerable freedom to decide how to realize the experiment. Cookbook-style directions model the use of laboratory vocabulary, describing techniques as well as equipment. With open-ended directions, the focus is on solving the problem.

\section{Learning café and pedagogical cafe}

Learning can be organized in an informal setting where discussions are conducted around 'coffee tables' in small groups. In some learning cafés, participants move freely from one table to another. On other occasions, a learning café is hosted by a moderator/facilitator and the movement between thematic tables is more carefully arranged. Learning cafés ideally foster learning through critical conversations. A pedagogical café specifically focuses on the development of teaching in order to support better learning.

\section{Pointers for students:}

- A learning café benefits from everyone taking an active role, sharing ideas, listening to one another, asking open questions.

\section{Pointers for educators:}

- Participants can benefit from being prepared beforehand for a learning café, knowing what to expect. Educators are responsible for careful planning of the topics to be discussed, orientation questions for launching the discussion, and giving a general orientation before participants divide into smaller groups. 


\section{Language and cultural considerations:}

The atmosphere should be supportive of everyone's participation whatever their language abilities. If this approach is very new for participants, a 'menu' of useful

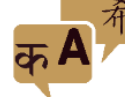
phrases can be on the tables to help keep the discussion moving. It is important to allow enough time for participants to become comfortable and to feel free to express themselves, and writing (shared) notes during the discussions can help to keep all participants involved. If this approach is new to participants, it can be useful to reflect on what was learned through this experience.

\section{Learning diary}

A learning diary is a written reflection on what is being learned during a course. A learning diary includes summarized course content, as well as a student's developing understanding in response to course contents (lectures, readings, discussions). A learning diary should include a student's own views, ideas, questions, concerns, and impressions. Over time these views should be increasingly substantiated and include critical reflections on phenomena connected to the course content. The scope of a learning diary is similar to an essay. In some cases the learning diary is a course requirement, and course-specific instructions should be provided. Using a reflective learning diary template, such as the following, can be a good starting point:

https://studysites.sagepub.com/burnsandsinfield3e/study/Chapter\%2023/Reflective\%2 Olearning\%20diary\%20template.pdf

\section{Pointers for students:}

- Start writing a learning diary from the first session of the course. Course materials and lecture notes are only part of the content of the diary, your thoughts, critical analyses, observations and arguments are also important to include.

- Additional academic reading can generate more source material for the learning diary and giving your diary an interesting title can help you to develop your focus.

- A learning diary is a chance to observe and assess the learning process and analyse the development of your learning. Occasionally re-read your entries to see how your ideas have developed during the course and writing process.

\section{Pointers for educators:}

- A good learning diary reflects the student's own thought and learning processes, and is the result of the 'dialogue' between the student and the new information introduced in the course.

- It is helpful to make the purpose of the diary clear and to have the grading rubric readily available if the diary is being used as an assessment tool. 
- Sharing unfinished or personal responses to a topic might be a new or demanding activity for some students. Asking students to select extracts from their learning diary can be a helpful way of drawing on their diary without making students feel over-exposed.

\section{Language and cultural considerations:}

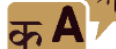

A learning diary may be a new academic exercise for many students. At its best, a learning diary will help develop self-understanding and provide another gateway to broaden thinking and perspectives in an intercultural context. Reflecting on short extracts can help students understand their own thoughts, values and emotions, and identify strengths and areas for development. Sharing extracts can also help students to recognize that each person writes, thinks and assimilates learning in unique ways and also creates a space for using different languages.

\section{Lectures}

This conventional mode of academic study is usually the place where the key theoretical content and examples of the subject matter are publicly presented either physically or online. Handouts might be provided before or after the lecture, but it is advisable to follow the lectures actively and to take notes. Lectures are not meant to be monologues; they should provide opportunities to present questions and generate dialogue.

\section{Pointers for students:}

- Read and reflect on relevant material before the lecture to get an idea of what might be covered. To get the most out of lectures revisit your notes after the lecture and develop a system for note taking.

- Make use of any references given at the end of a lecture; these point you towards valuable additional resources for furthering your understanding of the topic.

\section{Pointers for educators:}

- The flipped learning approach recommends that students are given relevant readings and key questions to consider prior to the lecture in order to support better quality discussion in response to the lecture.

- Online tools increasingly provide spaces for students to respond, share ideas and ask questions during lectures. Providing critical questions at the start of a lecture can help participants focus their attention and contributions. 


\section{Language and cultural considerations:}

A flipped approach can give students an opportunity to become familiar with key terms and expressions before the lecture. Students with multilingual repertoires

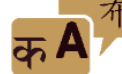
can be encouraged to discover how key concepts are named in different languages and to critically reflect on the different perspectives that they provide. It is a good idea to clarify the protocols for dealing with interruptions and asking questions within a group.

\section{Lecture diary / learning log 1}

A lecture diary or learning log should contain an account of and reflections on your learning and not simply a chronological list of events. A lecture diary or learning log should improve students' knowledge and understanding of topics by obliging them to think about them carefully in order to record them accurately. Learning diaries can also be referred to as learning logs, lecture diaries or learning journals. The texts can be written for students' personal use or shared (partly or entirely) with peers and/or the teacher.

\section{Pointers for students:}

- This is a place to freely explore ideas and raise questions.

- It is a good idea to freely write in the learning diary on a regular basis during a course.

- The text can be edited later if it is to be shared, and it also provides an important starting point for writing other assignments.

\section{Pointers for educators:}

- Instructions on format and writing style should be clarified when the task is assigned.

- It is important to make it clear which parts are personal and whether all or just some will be shared. It is also important to clarify whether the lecture diary is required but not evaluated, or whether it is also an evaluated task.

\section{Language and cultural considerations:}

Lecture diaries and learning logs can be important spaces for students to use different languages as resources for their studying; for example, being free to write in another language without fear of evaluation or thinking through course content through different languages. Students may feel vulnerable when required to write freely and to share this kind of writing. Clarifying the function of the text is therefore very important. 


\section{Note-making / note-taking}

Note-taking involves writing down the key points from readings and lecture notes, whereas note-making involves writing down key points in your own words. Many different kinds of approaches can be used when making and/or taking notes. Some students effectively use digital tools, whereas others can benefit from writing by hand or even including images. It is often helpful to include critical responses to notes, to add questions and different responses to course content. Developing a systematic approach to the vast amount of information encountered during academic studies is an important part of the studying process.

\section{Pointers for students:}

- Try out different ways of taking and making notes to find a way that works well for you. It can take time to develop your own system, but it helps a lot in the long run.

\section{Pointers for educators:}

- Encourage students to engage with study materials in different ways rather than just replying on either their memory or the camera function on their phone.

\section{Language and cultural considerations:}

Different languages can be used for taking and making notes. Consider the purpose of the activity and which language best supports studying. Often students become accustomed to particular ways of taking and making notes. Over time, this can seem like the only option. Take time to explore different ways every so often to ensure that students develop ways of studying that are good for them.

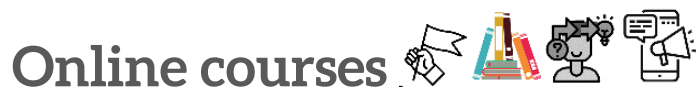

Online courses are generally conducted through a learning management system, in which students can view course syllabi, academic progress, and communicate with other participants. Basic online courses might use simple webpages or emails with links to materials and the assignment, with an arrangement for how to return the assignment (e.g. via email or a web folder). Hybrid courses can include on-campus activities, as well as online activities. Online courses often involve using a range of tools, such as video conferencing tools, interactive and collaborative activities and assignments, and even AR and Al solutions. Increasingly, online courses use learning analytics to monitor and facilitate progress through the different components of a course. Although online courses and distance learning opportunities have long been provided by open 
universities and other specialized institutions, in the current environment traditional higher education institutions are also providing education through online channels.

\section{Pointers for students:}

- Although you may not meet your teachers and classmates in person, try out different practices that support regular communication, such as live video feeds and chat forums. These practices can help create a more inclusive and immersive experience.

- Online courses can include independent work and group work with a variety of means for assessing and demonstrating progress, such as individual and group projects or online presentations.

- Some online courses may include and require an e-exam or completion of a set of assignments that can perhaps be completed more flexibly with respect to location and time.

- If you have difficulty accessing the learning platform, materials or activities, inform the course instructor.

\section{Pointers for educators:}

- Educational design for online environments might need more attention than some more traditional and familiar modes.

- Differences between access to a good computer and fast, reliable internet access should be taken into account in educational design with, for example, flexible timelines and alternative forms of course completion made available if needed.

- Online courses also require interaction, direction, and feedback. Live (video/ conversation-based) interaction, discussion forums and chat functions can engage students in valuable conversations around content.

- Clear, unambiguous evaluation criteria are especially important when there is no live or online face-to-face interaction. Assessment can include multiple means of demonstrating learning. Open forums where students can, anonymously or privately, ask for clarification and instructions are useful.

\section{Language and cultural considerations:}

International online courses provide opportunities for learning and using different languages. Depending on the educational design and course aim, mixing groups with different cultural and language backgrounds might be easier than in live settings. Virtual mobility and virtual transfer can provide opportunities that might broaden experience through immersion in different educational environments, cultures and expertise in safe, sustainable ways. One should take into account the potential variety of participant groups' traditions and working practices, including their expectations and ideas regarding quality education. 


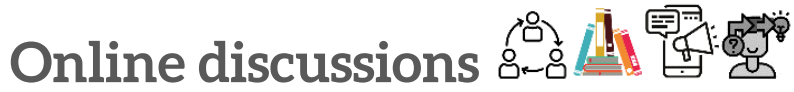

Online discussions can be integrated into many different courses, often with the help of a digital platform offering a safe environment for the exchange of ideas. Online discussions can be timetabled events or follow flexible schedules. Instructors might ask each student to make a minimum number of contributions or allow a freeform discussion to develop. Although online discussions facilitate interaction over a much greater space and time, the same basic rules of academic interaction are still relevant - pay attention to what others say, try to look from different perspectives, ask questions, be prepared to give reasons for your responses, and draw on course material to develop your arguments.

\section{Pointers for students:}

- Understanding the purpose of the online discussion will help you to develop your contribution and to respond to the contributions of others.

- Ideally, the online discussion will be thought- provoking and support critical inquiry.

- Do draw on course literature to develop your ideas and contribution. In keeping with good academic practice, always cite any academic references you use.

\section{Pointers for educators:}

- Guidelines on the goals of the discussion and, if the discussion is assessed, on a systematic grading rubric can support student participation.

- Online discussions can help students engage more deeply with academic content. Teacher contributions, whether in the form of feedback or quick questions, are also often appreciated.

- Sometimes the quality of student responses is greater than the quantity of responses.

\section{Language and cultural considerations:}

Online discussions can support intercultural groups, giving students flexibility

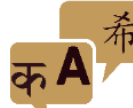
and time to work on their comments and responses. Online language tools, such as glossaries or dictionaries, can also be linked to digital platforms, and participants can benefit from the option of including multimodal contributions, e.g. a sketched idea, or jointly using concept-mapping tools (e.g. cmap). Online discussions can complement faceto-face interactions; both formats can benefit from establishing basic ground rules to encourage equitable relational dynamics. Online initiatives should always include detailed information about the way in which live interaction is arranged with, for example, time differences being taken into account. Attention should be given to ensuring the quality of audio transmissions, such as: 1) peaceful location, 2) microphone and speakers (preferably 
headset), and 3) familiarity with the settings needed for participation. Instructions and requirements must be communicated carefully.

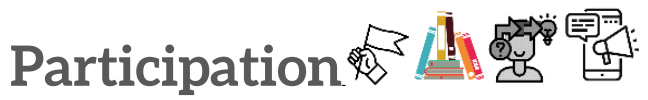

Participation is a key word in academic study and is often used as a basis for evaluation. Participation, in short, means that students actively engage with the subject matter and the studying process. This means that participation can take many forms and while, on the one hand, active participation supports individual student development, it can also support peer learning and build a collective thinking process in the classroom environment. Active participation often helps to improve learning relationships in the classroom space.

\section{Pointers for students:}

- Find a participation method that works for you, It could be commenting on an academic article, sharing questions relevant to the content of discussion, bringing to the class stories from one's study or work experience that complements the discussion and creates a ripple of new thoughts and ideas.

- Prepare yourself ahead of class by completing the reading tasks and highlighting and summarizing the material you would like to share with the class.

- Your participation should ideally demonstrate a higher level of thinking that goes beyond simply reading the assigned material and add to the collective critical thinking process.

\section{Pointers for educators:}

- Students can benefit from allowing diverse forms of participation. Plan the course using pedagogical methods that will actively support participation: working in pairs, reading circles, sharing summaries of learning, contributing to discussion boards during class sessions, etc.

- If student participation is part of the final course grade, it is important to consider different ways in which students can participate, whether in-class or online, individually or in groups, through spoken, written or enacted tasks, and what barriers to participating they might face.

\section{Language and cultural considerations:}

Encourage students to use the full-range of their resources to participate in their

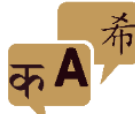
studies and in courses. For example, critically considering how to use different languages, e.g. writing/mapping ideas, developing shared channels of communication, sharing experiences and understanding from different perspectives, encouraging students to ask questions of each other and to be willing to develop understanding together. Ensuring that all participants understand the key concepts and aims of courses and individual sessions 
can help focus contributions and encourage students to critically consider how they can participate.

\section{Peer support 品品}

Peer support benefits from cooperative and collaborative skills and supports the cocreation of knowledge and understanding as part of academic practice. Strong peer-topeer support facilitates community building among students and contributes to a positive learning environment. Peer support can come in many different forms, such as working in pairs, building mind maps of ideas together, taking different roles during group work, respecting diverse ideas, and offering constructive feedback. Peer support can be formally integrated into course activities, but it can also be fostered as part of the wider academic culture.

\section{Pointers for students:}

- Asking questions that stem from reflection and critical thinking are an important part of peer support and academic interaction.

- Try to be an active listener - acknowledging and making connections between contributions enriches learning interactions for all parties involved.

- Reflecting on team collaboration, the strengths and weaknesses experienced in working together helps to develop peer support skills and an atmosphere of constructive feedback.

\section{Pointers for educators:}

- Incorporate collaborative learning activities within the curriculum to encourage social interaction that supports studying and the co-creation of understanding.

- Approaches that encourage reflection and self-awareness help develop peer support as a positive feature of academic study. Group work, no matter how large or small, is a desired course of action for building peer support.

\section{Language and cultural considerations:}

Language differences and cultural experiences can significantly affect how students approach and respond to peer support. Recognizing the different ways in which peer support can be offered and valuing the contributions of diverse participants can significantly help students to work together and co-construct their understanding. Employing inclusive strategies is a crucial part of developing peer support in intercultural settings. 


\section{Photo essay}

A photo essay combines visuals and text to produce a thematic story. Once the theme is clear, create your own visual dictionary by taking photographs or using websites with authenticated access to free and dynamic photographs (e.g. https://unsplash.com/). The essay should depict a coherent thread of thought through the text using visuals to create an impactful essay with a clear purpose and message. Each photograph should hold the reader's attention, connecting them to, and drawing them along with, the thread of the essay. The visual-text combination can spark engaging and provocative thoughts and questions as the reader is guided through the essay.

\section{Pointers for students:}

- Choose compelling photographs with strong imagery to depict the story message you wish to convey.

- The images should maintain a connection with the main theme of the essay.

- Choose photos from sites that legally allow you to use them for study purposes. It is important to give credit to the photographers in the document.

\section{Pointers for educators:}

- A photo essay should be accompanied by an assessment rubric to give students a clear understanding of the expectations for the photo essay.

- Experiment with writing your own photo essay (e.g. your teaching philosophy statement or portfolio) to get a good grasp of the challenges and opportunities of this activity.

\section{Language and cultural considerations:}

Photos are an effective tool in multicultural contexts as they help students to visualize and connect to spaces, people and situations and build a range of diverse perspectives. As a visual medium, photos have a language of their own, reducing the text load and expanding the scope of an essay.

\section{Poster presentations 움}

A poster presentation communicates research and understanding on a topic in a visual, condensed format. The visual presentation should convey the key message of the poster, which can be expanded by a brief oral explanation. Poster presentations are useful media for visualizing concepts, key findings, connections between topics and critical questions requiring the presenter to creatively think about the purpose of the presentation and the message to be conveyed. This link provides guidelines on poster 
presentations using JYU templates: https://uno.jyu.fi/en/help-centre/communicationsand-public-relations/presentation-materials/poster

\section{Pointers for students:}

- A poster presentation offers you a creative, flexible space for presenting your research and understanding.

- The audience should be able to understand the message of the poster without the oral explanation, although an oral explanation can add more details.

- Templates can help you balance the amount of text and visuals. Don't overfill your poster, but be creative and try out different ideas to maximize its effectiveness.

\section{Pointers for educators:}

- Understanding the purpose of a poster presentation should help with the design and development of the poster.

- Students can benefit from critically considering different examples or poster templates together before developing their own poster.

- The evaluation criteria for poster presentations should go beyond the design and clarity of content.

\section{Language and cultural considerations:}

Poster presentations can creatively incorporate different working languages, supporting multilingual interactions. In addition to conventional question-answer sessions around a poster, placing Post-it notes and pens next to a poster can also encourage the audience to write questions or comments on the poster, generating dialogue on the poster and providing useful feedback for the presenter.

\section{Prewriting strategies}

Prewriting strategies help to develop a text, whether written or spoken. There are many different types of prewriting strategies. Some strategies help to generate ideas, such as brainstorming, free writing, and using different perspectives to approach a topic. Other strategies help organize ideas and build a bigger picture of the text, such as clustering, mind mapping, listing or comparing and contrasting. Only edit the texts towards the end of the writing process. If you begin by generating and organizing ideas based on the purpose of the text you will develop a better text that requires less time to be finalized. 


\section{Pointers for students:}

- A good text is rarely written in one go and although it can be frustrating to not start writing immediately, careful planning leads to much better text. Find a good space and set aside time to invest in the process.

- Try out different strategies to see which ones work well for you and use different strategies at different stages of the writing process. You might prefer thinking on paper, others might prefer using digital media.

\section{Pointers for educators:}

- Asking students to submit their draft texts - or extracts of drafts - can encourage students to see prewriting as part of the overall writing process.

\section{Language and cultural considerations:}

In the prewriting phase, it can be useful to think through and draw on different

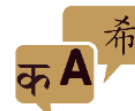
languages to generate and develop ideas. Once the actual writing phase begins, it may be better to consistently work through one language to develop a good text. Gaining feedback from others during the writing process can be extremely useful, and prewriting strategies can help pairs of students to share and generate ideas together, facilitating the development of a co-authored text.

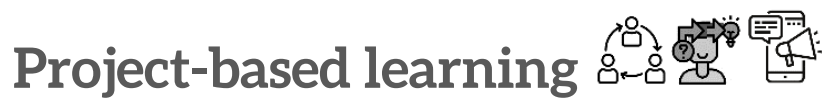

Project-based learning (PBL) is based on an authentic driving question and uses realworld challenges as the starting point for investigating, collaborating and developing understanding. Project-based learning brings together the needs of diverse learning communities and environments as well as transdisciplinary learning. The driving question can be answered with artefacts, such as models, reports, videotapes, programmes and games to be shared and critiqued.

\section{Pointers for students:}

- It will take time to find and form the right question to work with, but this is part of the studying process.

- Carefully consider how different subjects provide different ways to approach the same question and different resources to address the problem. 


\section{Pointers for educators:}

- Providing examples of driving questions can help students as they form their own ideas, e.g.: What kind of museum exhibition promotes learning of Sustainable Development Goals (SDGs) in basic education?

- As an applied form of learning, a wide range of artefacts can be developed through PBL.

\section{Language and cultural considerations:}

Language and cultural considerations: Some students may be unfamiliar with the more hands-on approach of project-based learning and under-estimate the intellectual demands of engaging with real-life challenges. Project-based learning, however, is an important opportunity to build connections between academic studies and life beyond the academy. Project-based learning is a good opportunity for students to use their full language repertoire and cultural experiences for gathering information and sharing what they produce.

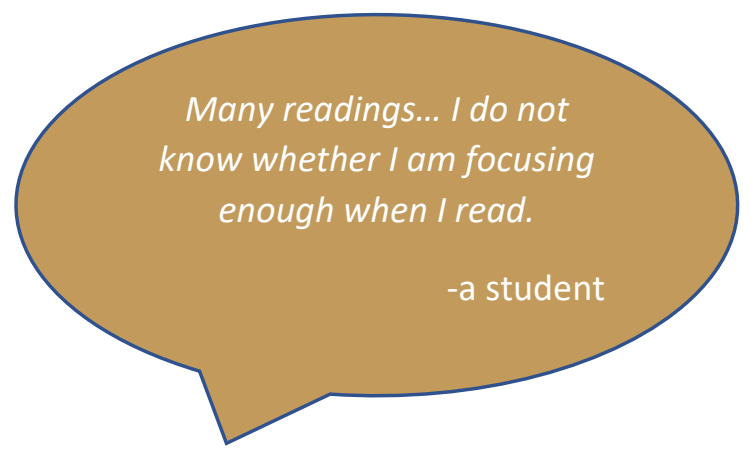

\section{Reading assignments 1}

Reading is a crucial part of academic study. Reading academic texts requires readers to navigate through different parts of a text and to critically engage with the contents. Although the keywords and abstract outline the central focus and message of a text, other sections serve different purposes. As a reader it is important to be able to identify the key points, the argument the writer is building, and the perspective the author is using. A reading assignment might require students to summarize the contents of an article, to compare and contrast different texts, or to provide a critical review of a text. The aim of reading assignments, however, is to encourage students to engage with the key literature connected with the area of study.

\section{Pointers for students:}

- Try to keep up with reading throughout a course - get into the habit of reading on a regular basis, take good notes, and try to find connections across the different readings that you are doing. 
- Reading assignments provide important material for class discussions and written assignments.

\section{Pointers for educators}

- Build a picture of the different readings that your students are doing and encourage them to build bridges across different courses and assignments.

- Encourage students to use different reading strategies as they engage with academic texts: anticipate content; take notes and ask questions; share and compare understanding.

- Require student discussions and group work to draw on the readings and allow students to combine readings with their own reflections and experiences.

\section{Language and cultural considerations:}

Reminding students of pre- and post-reading strategies can help them read more

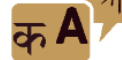
effectively, for example identifying and understanding key terms before reading, using different modalities to map. Multilingual groups have the advantage of being able to search for relevant literature in different languages when the course participants understand how to select and cite valid sources. For some students, critically responding to authoritative texts can be challenging, therefore practising different ways of reading and responding to texts can significantly help students to draw on readings in their own words.

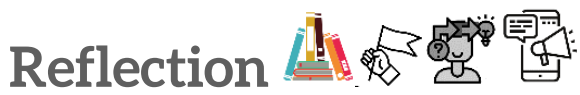

Reflection is an important part of critical thinking and plays an important role in integrating theory and practice. Reflection helps to take understanding beyond the taken-for-granted and recognizes the complexity of building understanding, for example, by identifying underlying assumptions and creating new connections. Developing a systematic approach to reflection requires practice.

\section{Pointers for students:}

- Although reflecting on your understanding can be challenging at first, this is an important skill to develop during your university studies.

- Reflecting with others in formal and informal settings generates rich discussions. Listening to others and asking questions helps to develop the metacognitive strategies of groups and individuals.

- By reflecting on your studies and progress, the overall learning experience will be more meaningful. Setting learning goals for yourself will help to focus your reflections and is a useful way of monitoring your progress. 


\section{Pointers for educators:}

- As with all skills, learning to reflect well often benefits from guidance. Providing questions to guide reflections and sharing your own reflections with the students can help the students enter into this process.

\section{Language and cultural considerations:}

As reflecting is a personal process, students can benefit from a supportive learning environment that is flexible enough to give participants sufficient time to think, share and respond. Sharing reflections together provides the participants with diverse perspectives and insights into how different students respond to the same course material or experiences. Some students, however, might be unused to sharing their reflections in a public learning space or surprised that they can use different languages as part of the reflection process. It is beneficial for multilingual students to have the opportunity to use their different languages to explore ideas and to critically reflect on their own development.

\section{Reflective sketchbook 1}

Reflective sketchbooks can be used as learning journals and as assignments to encourage students to reflectively and creatively work with new ideas and academic content. Reflective sketchbooks are a useful way of recording the thinking process including questions, ideas and insights, as well as offering a space for critiquing new ideas and looking from different perspectives. See also: Reflection and Visual methods and tools.

\section{Pointers for students:}

- You might be surprised by the playful, creative space of reflective sketchbooks in comparison to the regular culture of academic study. 'Playing' with the sketchbook can help to approach new ideas in different ways and to start to develop your own response to academic perspectives.

\section{Pointers for educators:}

- Development of motifs can encourage independent thinking.

- Assessment of reflective sketchbooks is not advised as this can limit the space for critical and creative participation, although sketchbooks can be used to verify students' active participation and provides insights into the unfolding of understanding.

- The sketchbook can serve as a tool for individual and collective reflections on a theme. 


\section{Language and cultural considerations:}

Reflective sketchbooks can ease the pressure to use formal academic language while still providing a valuable space to develop thinking and drawing on a range of resources and experiences to support learning. The step away from academic conventions can be challenging or disorienting for some students, although for others the use of different media can be liberating and inspire new ways of thinking and engaging with academic content.

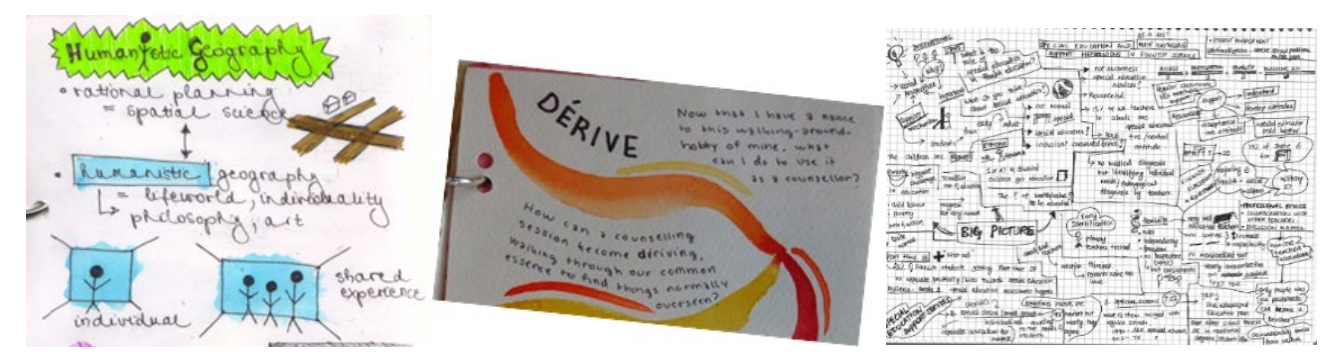

Figure 3. Illustrative pages from reflective sketchbooks (c) Josephine Moate

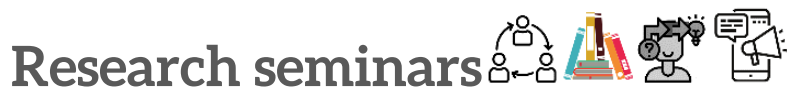

Research seminars aim to support students with their thesis process by providing a critical space where they can practise presenting, debating and reporting scientific understanding. Students will often present their own research in seminars, give feedback to their peers, and learn from others' topics, questions and insights. Shared themes and the overall thesis process can be more easily addressed in a thesis seminar.

\section{Pointers for students:}

- This is a space to think about research in general, as well as to examine the what, why and how of your own study.

- As a small group learning environment, research seminars encourage academic dialogue between student peers. The more you give to the seminar, the more you can benefit in your own thesis work.

\section{Pointers for educators:}

- Take into account different ways of communicating and the importance of respecting different backgrounds and levels of preparedness.

- It can also help if students share their writing or questions prior to the seminar, so each participant can come with some basic idea of each other's research and have some questions or input to contribute during the seminar. 


\section{Language and cultural considerations:}

Research seminars are valuable for building critical thinking and academic abilities. Allowing different ways to participate and being aware of the role of

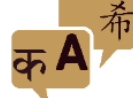
language and culture in the research process and seminar meetings are useful. Research seminars provide opportunities to develop good international research practices, such as bilingual presentations and acknowledging the role of different languages in conceptualizing research, as well as arguing for and justifying why particular approaches have been adopted. Collaborative and critical thinking can be encouraged to enrich the dialogic potential of the research seminar, e.g. by using infographics or visual aids.

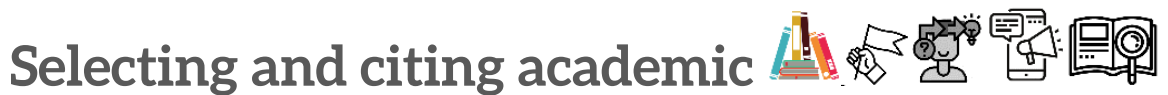

A fundamental part of academic writing is using reliable sources. The choice and range of sources indicates knowledge of the subject and adds credibility to the perspective or argument being presented. It is important to be aware of and to critically evaluate sources of information in order to be able to use and cite them appropriately. The Online Writing Lab (OWL) provides useful guidelines on citation conventions:

https://owl.purdue.edu/owl/research_and_citation/using_research/documents/20191212Citati onChart.pdf

\section{Pointers for students:}

- Sources of academic information can be varied and include books, articles, databases and encyclopaedia.

- It is advisable to use a variety of scholarly sources in your research so that you get the most complete and current information that can be validated across different sources.

- Evaluating an academic source for purpose, relevance, accuracy and authority is essential, e.g. is the author qualified to write on the topic, where is the information published, and has the publication been peer-reviewed.

\section{Pointers for educators:}

- Students often need a clear orientation to prepare them for using academic/scientific sources well.

- It is helpful to direct students to complete a basic library course on where and how to search for academic information.

- Academic referencing and citations are an integral part of selecting and using academic sources. Students often benefit from practising how to cite and use citation conventions in their work. 


\section{Language and cultural considerations:}

Google Scholar and many other library databases offer the flexibility of searching for articles on a topic and can facilitate finding academic sources in different languages. If students understand how to locate and evaluate different sources, this enables them to search for information in different languages and to draw on sources that the teacher might not be familiar with.

\section{Supervision: individual or group 1}

HOPS tutorials, meetings during teaching practice or internships and thesis seminars are examples of different forms of supervision. Supervision can be provided for individuals or in group settings. Supervision focuses on the learner's process rather than the content and should support students working towards a goal. An important part of supervision, however, is also providing the space for students to share their experiences of working within the given programmes or structures.

\section{Pointers for students:}

- Supervision is more beneficial if you are willing to share your struggles and questions. Remember that the aim of supervision is to help you with your studies.

- It is important to prepare for supervisory sessions, e.g. by completing readings and sending texts within a reasonable timeframe, and then reflecting afterwards on what was discussed and agreed.

\section{Pointers for educators:}

- Consider supervision as a critical learning opportunity to see familiar topics from the student's perspective.

- Supervision should help students to move forward as well as help them be aware of hindrances that can prevent progress.

\section{Language and cultural considerations:}

Students can have a range of different experiences and expectations regarding supervision. Some might expect to be given strict instructions and find the academic freedom of Finnish university life quite overwhelming. Others might find the academic freedom very refreshing. It is useful at the start of a supervisory relationship to agree what belongs to the supervisory process and to find clear ways of communicating expectations rather than assuming a shared understanding.

\section{Story circles}

Storytelling is an art and a form of facilitation that supports creativity and innovation in education. Story circles begin with a key question that is the focus of the activity. As the 
participants divide into small groups of three, each participant takes on a role, e.g. storyteller, harvester or witness. The Storyteller responds to the question by telling a story. The Harvester closely listens to the content of the story, and the Witness focuses on the person telling the story. After the story has been told, the Harvester and Witness both share what they 'heard' through the story. The roles can be rotated so that each person gets to be a storyteller, witness and harvester. Each story circle lasts for about 15 minutes, with 10 minutes for telling the story and 5 minutes for sharing back. It is helpful to depict the process graphically or with text. Resource:

http://www.globaltfokus.dk/images/Kapacitetsudvikling/indsatser/SOL_ressourcedatabase/1._T oolbox/Guide_Trio_Story_sharing.pdf

\section{Pointers for students:}

- Stories are a powerful medium for developing understanding and broadening participants' view of the diversity present in a student group.

- This activity involves active listening and listening with purpose, as well as feeding back what you have heard.

- After you have shared and listened to the stories, draw or write what you sense, feel or understand from the story.

\section{Pointers for educators:}

- This activity requires an open and trusting space where people can open up with stories of their personal or professional experiences. It is important for participants to understand how this activity connects with the aims of the course.

- As stories are being shared, the educator is a passive observer, although the educator can help harvest what is learned from each story by documenting them, e.g. on padlet or writing key points as text on a white board.

\section{Language and cultural considerations:}

Building relationship between participants is even more important in an

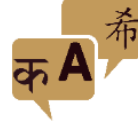
intercultural community. Although storytelling can naturally unfold under the right conditions, the feeling that story telling is 'non-academic' might inhibit participants if they don't understand the bigger purpose. Story circles can also create spaces for different languages to be used and thinking about how to bring the essence of the story circle back to the larger group can help participants to transition between languages. Story circles can also open participants' eyes and minds to the variety of cultural repertoires and experiences that can exist within a classroom. 


\section{Video lecture 110}

Video lectures are delivered or are available online rather than face-to-face. Video lectures offer flexibility for both teacher and students.

\section{Pointers for students:}

- Video lectures are usually a distinct part of an online course and a great tool for you studying at your own pace. Re-watch videos if it helps you to understand the content.

- Make notes of the key points covered in the lecture and add your own thoughts and questions. If there are activities during the lecture, take time to pause the lecture and focus on the task.

\section{Pointers for educators:}

- Use various strategies and tools to keep the video lecture engaging, interactive and to create active learning.

- Creating guided or embedded questions and tasks between videos can make it more interactive.

- Share the outline of the presentation at the beginning and a summary at the end of the presentation.

- Explore pre-existing videos on a topic and create complementary videos rather than completely building a fresh video from start.

- Use a suitable app to share the main content (presentations, graphs and drawings) on screen together with an embedded screenshot of the presenter. This helps observers to focus on the content of the presentation.

\section{Language and cultural considerations:}

Video lectures provide a possibility for creating videos in different languages and

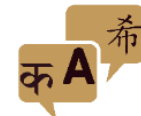
providing subtitles in alternative languages. The theme of the videos could include images from different cultural contexts to broaden the scope of the lecture. Currently, JYU is promoting ease-of-access, and video support is available for the addition of subtitles to video lectures. Students can also benefit from access to lecture slides or materials as they are listening to the lecture and working through the material.

\section{Video presentation 1}

Video presentations should create a digital connection between the presenter and the topic of interest. This connection is achieved through a combination of good scriptwriting, an engaging voice and well-timed dynamic visuals. 


\section{Pointers for students:}

- Try to come up with an overall design that combines different types of content in the video presentation, such as an interview, a narration or a demonstration.

- Consider: 'What is the key purpose of my video presentation?' and divide the content into logical parts.

- Scripting and practising your presentation will help you plan your presentation effectively.

- When selecting visuals, think in terms of imagery that reinforces the topic under discussion, rather than PowerPoint slides or onscreen text.

\section{Pointers for educators:}

- Encourage students to create a reference list of resources cited (or images/diagrams displayed) using the academic standards relevant to the discipline.

- Remind students to use copyright-friendly images.

- If recording rooms and equipment facilities are available for video productions, and if the student is working on a video for university purposes, guide them on the use of the facilities and copyright-related issues.

\section{Language and cultural considerations:}

Video presentations help provide the flexibility of having subtitles in other languages or presenting in a mother tongue language with subtitles in the common working language. Effective visuals and demonstrations can support producing multilingual video presentations.

\section{Visual methods and tools}

Visual methods go beyond words, written or spoken, to explore, present and capture ideas and understanding. Visual methods are more than taking snapshots of presented information, although snapshots can become part of visual thinking if further notes, illustrations or highlights are added to them. A variety of visual methods are available including: posters, infographics, creative presentations, visual databases, simulation environments and video-based tools for collaborative work. Useful online tools include word clouds, canva.com and powtoons.

\section{Pointers for students:}

- Visual tools can help to graphically present your ideas, conceptualize relationships between concept themes and sub-themes (mind maps, concept maps) and track progression of your learning goals.

- Visual tools can help you to develop your problem-solving and critical thinking skills. 
- These tools can help highlight the key learning in your assignment or essay and add more clarity and coherence for the reader.

\section{Pointers for educators:}

- Try to learn about different tools that are available and use students' knowledge of different tools to explore and benefit from visual methods and tools.

- Lecturers can effectively utilize visual tools to support the planning of lectures and tutorials, as visual learners struggle with listening to directions and information that is purely auditory.

\section{Language and cultural considerations:}

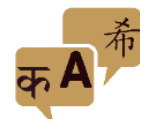

Using simple visual methods in multicultural class environments can help organize information and show relationships between concepts and the flow of a conceptual process. Visuals offer an effective alternative to large volumes of text when working in a language that not everyone may be fluent or competent in. Students can create visual maps in their own languages to support their own critical thinking and the communication of complex notions. Visuals can be presented in a variety of working languages and include supporting text.

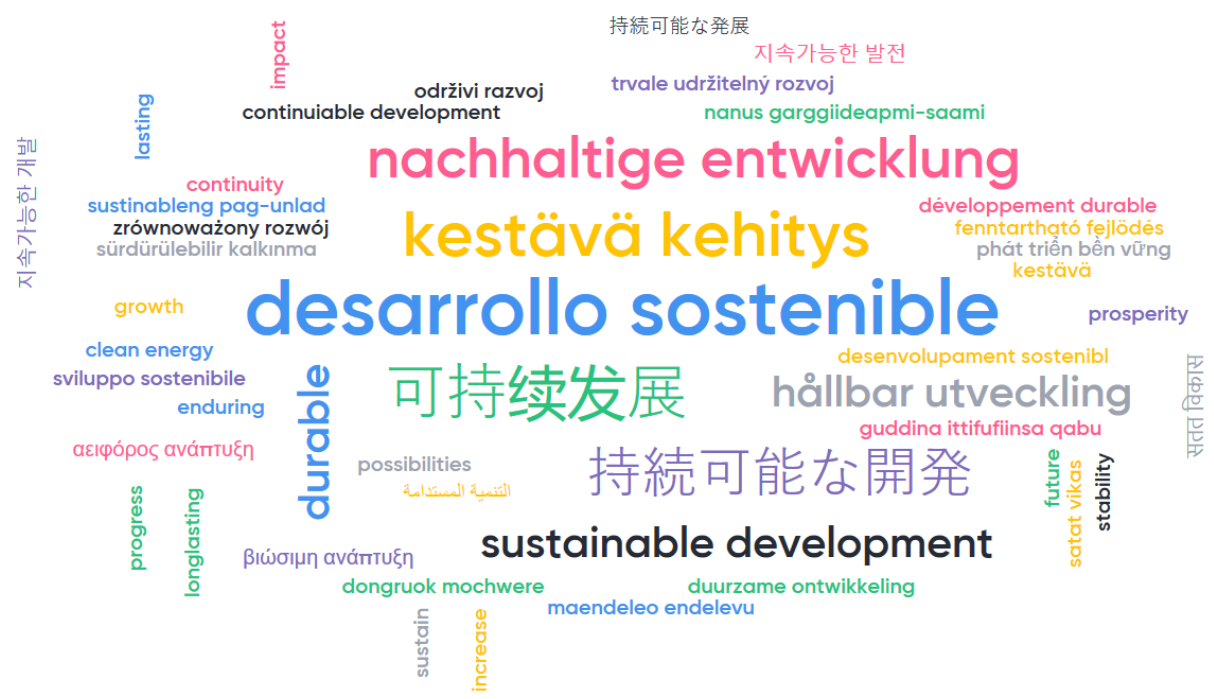

Figure 5. A word cloud created during the JYU SDG4 2019 seminar with www.mentimeter.com

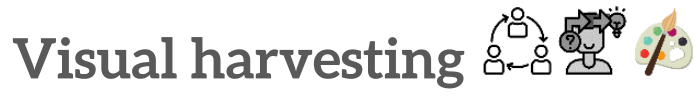

A 'visual harvest' is a description in the simplest form and is a method of processing and storing information using visuals combined with text. This is a creative process that aims to capture the essence of collective thought processes. The visual representation draws on the ideas of what people speak about in a meeting or conference and gathers the essence of what is being heard through a visual story. Visual harvesting facilitates group 
learning and cultural memory. Creating large pictures that integrate content, prompt insight, and aid decision-making taps into the collective intelligence of a group or community and builds potential for the synergy of a group.

\section{Pointers for students:}

- Visuals and text can be creatively combined to effectively bring out the meanings that are emerging in a group discussion or from an entire course. It can also highlight questions and areas that are grey and ambiguous, allowing for further questioning. It is essentially visual sense making.

\section{Pointers for educators:}

- As an extension to the idea of a mind map or just as a visual map, this process involves authentic deep listening in order to look for the essence underlying the words we hear and the text we read. It serves as a tool for further exploratory learning and group discussions led by powerful questioning. It can be an assessment tool, a learning tool, or a reflection tool. It helps to complement the visual harvest with an oral presentation of what it holds.

\section{Language and cultural considerations:}

The pressure to use complicated academic language is bypassed by highlighting key words, main concepts and sub-concepts as visuals and text. The visual part has a language of its own that is unique to the learner and the group. The major cultural variations in how a particular visual is understood should be given attention in this process. The visual must be inclusive and representative of the concept and community in question.

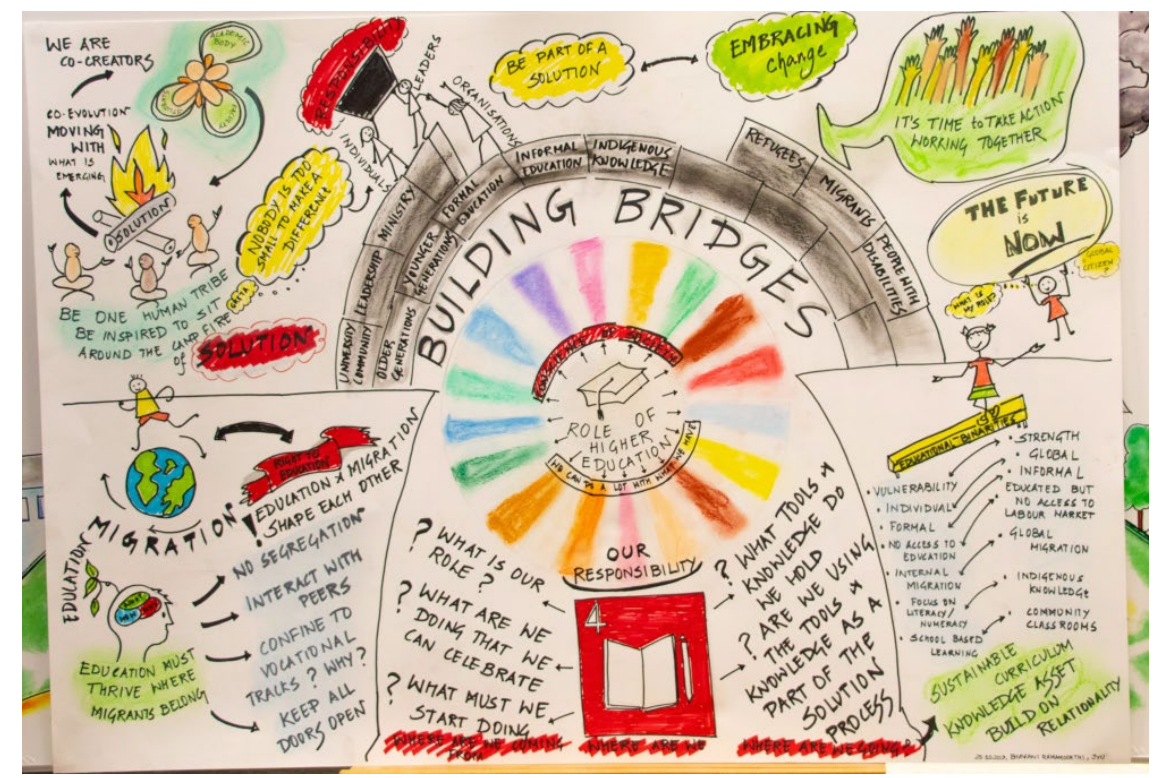

Figure 5. A visual harvest from the JYU SDG4 seminar 2019 @ Bhavani Ramamoorthi 


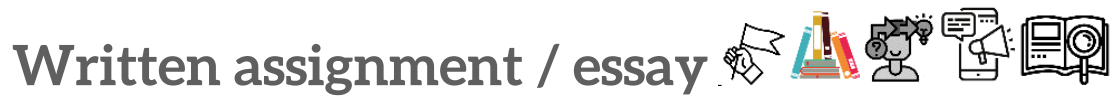

A written assignment or essay should be a coherent text that follows a systematic pattern with a clear introduction, body and concluding paragraph. Written assignments usually involve summarizing relevant knowledge from the course (e.g. lectures, readings) as well as demonstrating critical understanding. Although academic writing is demanding and involves several stages (planning, drafting, editing), it is an efficient way of learning and helps students to develop and combine their own ideas with the ideas from the source materials. This process requires time. https://www.jyu.fi/edupsy/en/studies/studyguide/essay-instructions

\section{Pointers for students:}

- When planning your essay, clearly define and limit the theme. Search for relevant literature and/or use the literature given for the assignment.

- Be aware that essays should have a clear and coherent structure and use formal language.

- As an academic text, references should be marked in the text and a list of references should be included at the end following the guidelines from APA 7. More instructions can be found e.g. from the JYU Centre for Multilingual Academic Communication resources. https://movi.jyu.fi/en/instructions/maturity-exam/advice-for-writing-anessay-type-text

\section{Pointers for educators:}

- Students can be overwhelmed by the demands of academic writing, especially when working through an additional language. Careful planning and building drafts can help students to develop their ideas.

- Carefully consider the required length of the text and whether students need help to understand the different types of essays or essay questions., e.g. to explain, compare, critique, and what they require from students. It can also be useful to model the planning process for writing an essay.

\section{Language and cultural considerations:}

It can take time and practice to really develop good academic literacy skills. It is worth considering when it is necessary to adhere to strict rules and when it is important

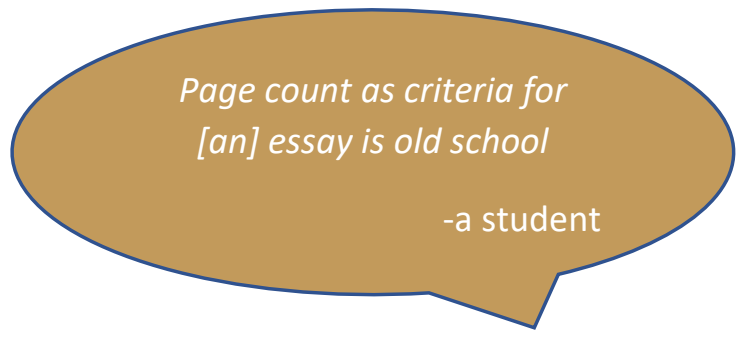


to give students space to develop their own voice as part of their academic development. Written texts are not the only mode that students can use to demonstrate their learning.

\section{Zines \% 궁}

A zine ('zeen') is an informal, creative format for small-scale visual presentations. A zine can use words as well as pictures (drawn, photographed, cut out) to explore ideas or themes and to report or share experiences. The visual, crafted nature of a zine encourages a student (author) to think carefully about the narrative that is unfolding, as well as the conceptual background of the piece. This open-ended format can be used in different ways. See the links below for how to create the physical zine - the content will depend on the assignment and purpose of the zine!

https://www.wikihow.com/Make-a-Zine

https://www.youtube.com/watch?v=9INUang4oMA

\section{Pointers for students:}

- Using zines gives an opportunity to explore the topic from different perspectives and new dimensions. Use your creativity and the diverse visual and linguistic resources at your disposal.

\section{Pointers for educators:}

- Using zines allows students to draw on their creative resources and express their ideas. The value of this creative format needs to be made explicit.

\section{Language and cultural considerations:}

As a countercultural mode of expression, zines offer a space for exploring different perspectives without being restricted to conventional and academic formats. This more creative space can be useful when dealing with more sensitive topics, such as identity development or relationships with place, and supports sense-making. 


\section{GLOSSARY}

\begin{tabular}{|c|c|c|}
\hline Annotated bibliography & $\begin{array}{l}\text { Kommentoitu } \\
\text { kirjallisuusluettelo }\end{array}$ & 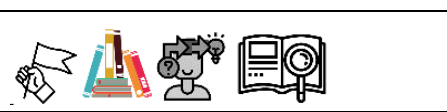 \\
\hline Assessment & Arviointi & \\
\hline $\begin{array}{l}\text { Assignments: learning } \\
\text { journals, essays, reading } \\
\text { tasks, group presentations }\end{array}$ & $\begin{array}{l}\text { Oppimistehtävät: } \\
\text { oppimispäiväkirjat, } \\
\text { esseet, lukemistehtävät, } \\
\text { ryhmätyöt }\end{array}$ & 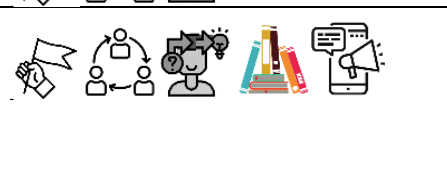 \\
\hline Book exam/eExam & Kirjatentti/eTentti & 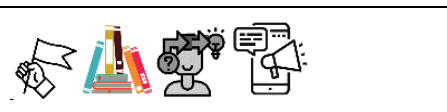 \\
\hline Classes & Opetus/Kontaktiopetus & \\
\hline $\begin{array}{l}\text { Conversation mapping or } \\
\text { silent dialogue }\end{array}$ & $\begin{array}{l}\text { Keskustelukartta tai } \\
\text { hiljainen dialogi }\end{array}$ & 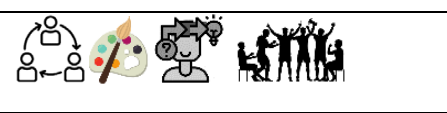 \\
\hline Creative writing & Luova kirjoittaminen & 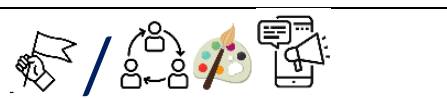 \\
\hline Critical thinking & Kriittinen ajattelu & \\
\hline Debates & Väittelyt & \\
\hline Demos (demonstrations) & Demot (demonstraatiot) & \\
\hline $\begin{array}{l}\text { Designing powerful } \\
\text { questions }\end{array}$ & Tehokkaat kysymykset & 客 \\
\hline $\begin{array}{l}\text { Digital learning } \\
\text { environments and } \\
\text { platforms }\end{array}$ & $\begin{array}{l}\text { Digitaaliset } \\
\text { oppimisympäristöt ja } \\
\text { alustat }\end{array}$ & 我: \\
\hline Distance learning & Etäopiskelu & 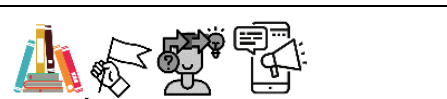 \\
\hline Drama & Draama & Mithes \\
\hline $\begin{array}{l}\text { Examinations: individual, } \\
\text { written, group oral exam }\end{array}$ & $\begin{array}{l}\text { Tentit: yksilö-, ryhmä-, } \\
\text { kirjallinen- ja suullinen } \\
\text { tentti }\end{array}$ & 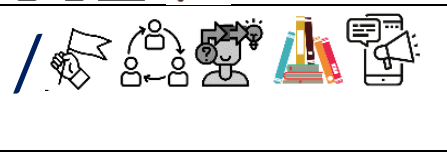 \\
\hline Feedback (peer, group) & $\begin{array}{l}\text { Palaute (vertais- tai } \\
\text { ryhmäpalaute) }\end{array}$ & 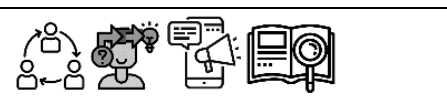 \\
\hline Fieldwork & Kenttätyö & 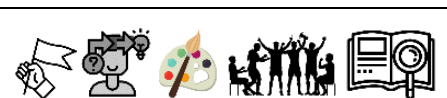 \\
\hline Gallery walk & $\begin{array}{l}\text { Näyttelykävely, } \\
\text { galleriakävely }\end{array}$ & 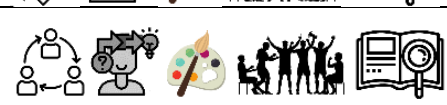 \\
\hline Group presentations & Ryhmätyö esitelmä & 명 \\
\hline
\end{tabular}




\begin{tabular}{|c|c|c|}
\hline Group work & Ryhmätyöskentely & 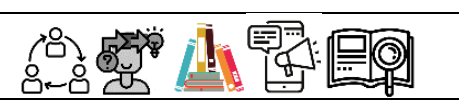 \\
\hline $\begin{array}{l}\text { Independent tasks and } \\
\text { activities }\end{array}$ & $\begin{array}{l}\text { Itsenäiset } \\
\text { oppimistehtävät }\end{array}$ & 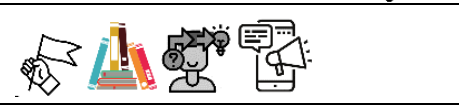 \\
\hline Independent learning & Itsenäinen opiskelu & 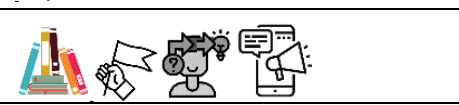 \\
\hline Infographics & $\begin{array}{l}\text { Infografiikat (tai } \\
\text { infogrammit) }\end{array}$ & 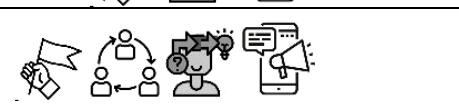 \\
\hline Integrative modes of study & $\begin{array}{l}\text { Integroivat } \\
\text { opiskelumuodot/ } \\
\text { opiskelutekniikat }\end{array}$ & 3 \\
\hline Laboratory work & Laboratoriotyöskentely & 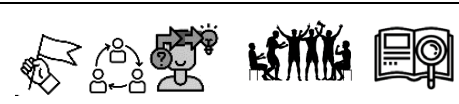 \\
\hline $\begin{array}{l}\text { Learning café and } \\
\text { pedagogical coffees }\end{array}$ & $\begin{array}{l}\text { Learning café ja } \\
\text { pedagoginen kahvila }\end{array}$ & 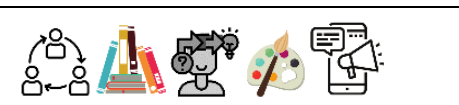 \\
\hline Learning diary & Oppimispäiväkirja & 紫国: \\
\hline Lectures & Luennot & 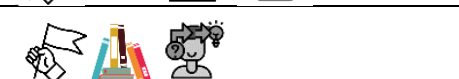 \\
\hline Lecture diary / learning log & Luentopäiväkirja & 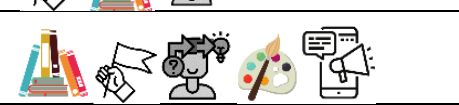 \\
\hline Note-making / note-taking & $\begin{array}{l}\text { Muistiinpanojen } \\
\text { tekeminen }\end{array}$ & 留 $\%$ \\
\hline Online courses & Verkkokurssit & 兽国血: \\
\hline Online discussion & \begin{tabular}{|l} 
Verkkokeskustelut \\
\end{tabular} & 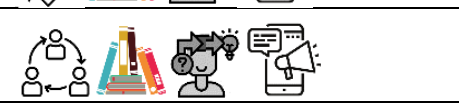 \\
\hline Participation & Osallistuminen & 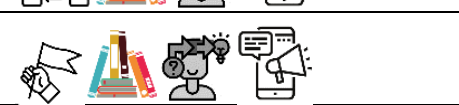 \\
\hline Peer support & Vertaistuki & \\
\hline Photo essay & Valokuvaessee & 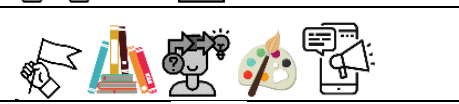 \\
\hline Poster presentations & Posteriesitykset & 6. \\
\hline Prewriting strategies & \begin{tabular}{|l|} 
Kirjoittamisen strategiat \\
\end{tabular} & 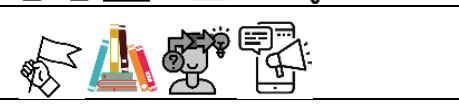 \\
\hline Project-based learning & Projektioppiminen & 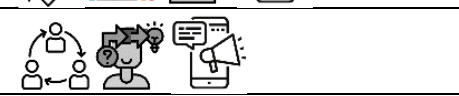 \\
\hline Reading assignments & Lukemistehtävät & 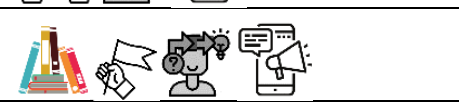 \\
\hline Reflection & Reflektio & 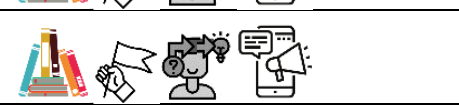 \\
\hline Reflective sketchbook & \begin{tabular}{|l|} 
Reflektiiviset \\
luonnosvihkot
\end{tabular} & $11 \%$ \\
\hline Research seminars & Tutkielmaseminaarit & 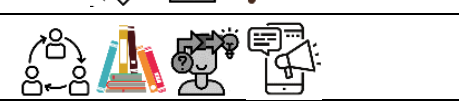 \\
\hline
\end{tabular}




\begin{tabular}{|l|l|l|}
\hline $\begin{array}{l}\text { Selecting and citing } \\
\text { academic sources }\end{array}$ & $\begin{array}{l}\text { Akateemisten lähteiden } \\
\text { valitseminen ja niihin } \\
\text { viittaaminen }\end{array}$ \\
\hline $\begin{array}{l}\text { Supervision: individual or } \\
\text { group }\end{array}$ & Yksilö- ja ryhmänohjaus \\
\hline Story circles & Tarinarinki & Videoluento \\
\hline Video lecture & Videoesitelmä & $\begin{array}{l}\text { Visuaaliset menetelmät } \\
\text { ja työkalut }\end{array}$ \\
\hline Video presentation & $\begin{array}{l}\text { Visuaalinen sadonkorjuu } \\
\text { (kuvakiteytys, } \\
\text { visualisointi) }\end{array}$ & Kirjoitustehtävä/essee \\
\hline Visual harvesting & Zine-muotoiset esitykset \\
\hline Written assignment / & Zines
\end{tabular}

